Journal of Geophysical Research: Oceans

\section{RESEARCH ARTICLE \\ 10.1002/2014JC010145 \\ Key Point: \\ Heat balances and thermally driven lagoon-ocean exchangeson a tropical coral reef system (Moorea, French Polynesia)}

- Surface heating patterns drive exchange and export of heat

Correspondence to:

L. M. M. Herdman,

livmw@stanford.edu

\section{Citation:}

Herdman, L. M. M., J. L. Hench, and S. G. Monismith (2015), Heat balances and thermally driven lagoon-ocean exchangeson a tropical coral reef system (Moorea, French Polynesia), J. Geophys. Res. Oceans, 120, 1233-1252, doi:10.1002/2014JC010145.

Received 12 MAY 2014 Accepted 30 DEC 2014 Accepted article online 7 JAN 2015 Published online 25 FEB 2015

\author{
Liv M. M. Herdman ${ }^{1}$, James L. Hench ${ }^{2}$, and Stephen G. Monismith ${ }^{1}$ \\ ${ }^{1}$ Environmental Fluid Mechanics Laboratory, Stanford University, Stanford, California, USA, ${ }^{2}$ Duke University Marine \\ Laboratory, Nicholas School of the Environment, Beaufort, North Carolina, USA
}

\begin{abstract}
The role of surface and advective heat fluxes on buoyancy-driven circulation was examined within a tropical coral reef system. Measurements of local meteorological conditions as well as water temperature and velocity were made at six lagoon locations for 2 months during the austral summer. We found that temperature rather than salinity dominated buoyancy in this system. The data were used to calculate diurnally phase-averaged thermal balances. A one-dimensional momentum balance developed for a portion of the lagoon indicates that the diurnal heating pattern and consistent spatial gradients in surface heat fluxes create a baroclinic pressure gradient that is dynamically important in driving the observed circulation. The baroclinic and barotropic pressure gradients make up $90 \%$ of the momentum budget in part of the system; thus, when the baroclinic pressure gradient decreases $20 \%$ during the day due to changes in temperature gradient, this substantially changes the circulation, with different flow patterns occurring during night and day. Thermal balances computed across the entire lagoon show that the spatial heating patterns and resulting buoyancy-driven circulation are important in maintaining a persistent advective export of heat from the lagoon and for enhancing ocean-lagoon exchange.
\end{abstract}

\section{Introduction}

Coral reefs are valuable ecosystems threatened by many human activities including thermal stress from global warming, ocean acidification, and impaired water quality [McClanahan, 2002]. Large water temperature fluctuations and thermal stress are problematic for corals and can lead to coral bleaching [Davies et al., 1997; Hoegh-Guldberg, 1999]. However, the interaction of corals with their thermal environment is complex; the ultimate response additionally depends on other stressors such as light, sediment, wave forcing, sea level, and species interactions [Glynn, 1996; McCook, 1999; McClanahan, 2002]. The thermal stress required to induce bleaching has been found to depend on prior organismal thermal climatology, including long and short-term patterns of water temperature and temperature variability [Sammarco et al., 2006; Manzello et al., 2007]. Understanding the mechanisms that determine the thermal climate of reefs and the residence time of materials on reefs is important for understanding the resiliency of coral reefs in the face of these stressors.

Reef thermal variability (i.e., spatial and temporal deviations from climatology) can be driven by atmospheric forcing (e.g., solar radiation, wind, and surface heat fluxes) [Smith, 2001; Wells et al., 2012; Zhang et al., 2013], as well as oceanic advective and mixing processes from tides [McCabe et al., 2010], internal waves [Leichter et al., 2005], thermocline displacements from mesoscale eddies [Davis et al., 2008], wind stress [Nadaoka et al., 2001], and wave-driven flow [Davis et al., 2011]. The combination of local heat fluxes and variability in advective forcing can lead to significant daily temperature variability at basin scales [Leichter et al., 2006], reef scales [Leichter et al., 2005; McCabe et al., 2010; Davis et al., 2011], and the scales of a coral colony [Ong et al., 2012]. Smith [2001] also observed that in addition to advection, wind and the resulting local cooling was necessary to include in predicting temperatures for reefs in the Bahamas. Zhang et al. [2013] found a strong relationship between longer residence times and an increased reef temperature relative to the ocean, due to longer interactions with atmospheric forcing.

The aforementioned studies have largely focused on how advection and atmospheric conditions can affect water temperature on reefs; however, less work has been done on the inverse relationship, where heat 
fluxes have a dynamical effect on circulation and residence time on coral reefs. Differential heating has been observed as a mechanism for cross-shore and cross-reef exchange [Monismith et al., 2006]. Differential heating can occur in locations with depth variations, since shallower water has a faster temperature change for a given surface heat flux creating a horizontal gradient in depth-averaged temperature, which can drive baroclinic exchange flows. Niemann et al. [2004] found this physical mechanism was responsible for transporting phytoplankton rich waters offshore in the Red Sea. Additionally, in a study of the Florida Keys reef tract [Gramer et al., 2012], the long-term heat balance could not be explained without including thermally driven circulation.

Similar dynamics have been described in other environments including lakes and reservoirs [Monismith et al., 1990; Dittko et al., 2013], and on land with sea breezes [Physick, 1976]. Mao et al. [2009] studied this phenomenon using numerical simulations of spatially invariant heat fluxes on sloping bottoms to find the resulting steady state circulation. In all of these studies, the critical feature has been a linearly sloping bottom. Moreover, in natural systems, the diurnal period of heating and cooling can result in an unsteady flow. The primary momentum balance in flows driven by surface heat fluxes on a variable depth bottom is often between inertia and buoyancy, allowing a lag to occur between the forcing from surface heating and the flow that develops. The circulation arising from the interaction of linearly sloping bathymetry and timedependent heating and cooling has been described as a "thermal siphon" [Monismith et al., 2006].

Herein we describe similar dynamics, but in a system that does not have the gradually sloping bottom characteristic of previous studies. We describe a shallow coral reef and deep lagoon that is composed of discrete areas of different depths connected to each other and the ocean by channels. We describe the thermal environment and explore the role of thermally driven circulation on residence time and the ocean-reef exchange. To gain a better understanding of the complex interactions between heat flux and residence time in this system, we develop a heat budget for different parts of the reef and explore the average diurnal variability in flows and temperature. We examine the role of temperature in the overall dynamics as well as the contribution of horizontal temperature gradients to circulation and residence time. The structure of the paper is as follows. In section 2, we discuss the field site and measurements. In section 3, a thermal balance is proposed for distinct sections of the reef as well as a momentum budget where horizontal temperature differences provide a driving force. At the end of section 3, the sum of heat balances from the reef subsections is used to estimate a heat budget for the entire reef. Finally in section 4, we discuss how temperature gradients modify and drive the overall circulation patterns and residence times in the bay before concluding with section 5 .

\section{Methods}

\subsection{Field Site}

Moorea $\left(17^{\circ} 32^{\prime} \mathrm{S}, 149^{\circ} 50^{\prime} \mathrm{W}\right)$ is a high island (peak elevation $=1200 \mathrm{~m}$ ) in French Polynesia that has an extensive fringing reef and lagoon system [Galzin and Pointier, 1985]. The bathymetry and configuration of the reefs surrounding this island is a common reef structure throughout the tropical Pacific. Lagoons and deep channels separate the reef from the island, and there are deep passes through the barrier reef connecting the lagoons to the ocean. The two largest passes and lagoons on Moorea are on the north shore, and the eastern one of these is Paopao Bay, where the field measurements were made (Figure 1).

There are four main parts to the Paopao Bay system: a steeply sloping fore reef, a shallow back reef, a deep bay, and a reef pass that connects the back reef and bay to the ocean. The shallow back reef spans $1 \mathrm{~km}$ from the shoreline to the reef crest with mean depths of 1-3 m interspersed with massive coral colonies (mainly Porites spp.) and rough topography [Hench and Rosman, 2013]. The deep bay is approximately $3 \mathrm{~km}$ long, $1 \mathrm{~km}$ wide, and 20-30 m deep. The bay's bottom is sand and silt while there are coral colonies along the shallow edges. The southern end has a small freshwater stream from the Paopao Valley that has little flow except during local rain events. The north end of the bay is bounded by the confluence of two channels draining the back reef, and Avaroa Pass (approximately $300 \mathrm{~m}$ wide and $40 \mathrm{~m}$ deep), which connects the back reefs and lagoon system to the ocean. The pass bottom is mostly coral rubble and the channels are sandy, neither have live coral. Tides are relatively weak due to a combination of the small tidal range $(\sim 0.2 \mathrm{~m})$ and small tidal prism, such that the primary external input of momentum for forcing flows through the system is from wave breaking. Waves breaking on the fore reef (North of R1) drive circulation across the 

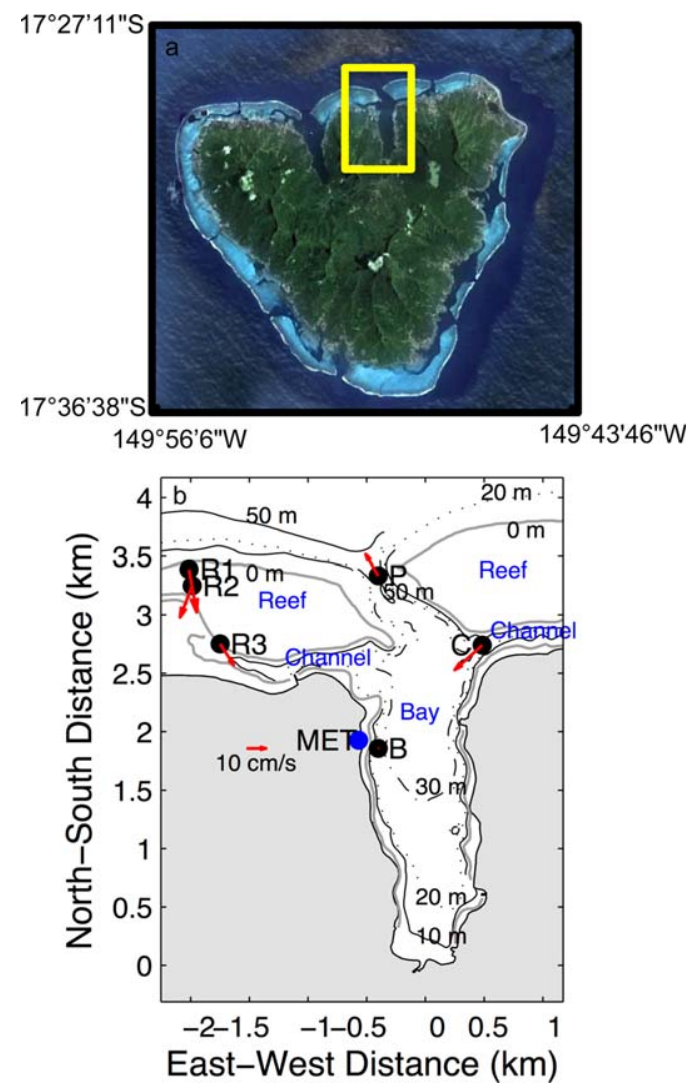

Figure 1. (a) Satellite image of field site (source: Google Earth $\odot$ ); (b) bathymetry of Paopao Bay and locations of moorings and met station. Station labels (single letters in black) match descriptions of mooring deployments in Tables 1 and 2. At each mooring location, a red arrow shows the depth-averaged currents, the current at B is very small thus the arrow is very small. The blue text indicates the names of the locations referred to in the text. highly frictional back reef (from R1 to R3) through the lagoon and out of the reef pass [Hench et al., 2008; Rosman and Hench, 2011; Monismith et al., 2013].

\subsection{Field Measurements}

Data were collected during two intensive austral summer field experiments during December 2006 to February 2007 and December 2008 to February 2009. We deployed an array of acoustic current profilers, CTDs, and temperature sensors that spanned the back reef, lagoon, and reef pass (Figure $1 \mathrm{~b}$ ). Tables 1 and 2 describe the instrumentation and sampling frequency at each mooring for each of the two experiments. Mooring locations were the same for both deployments. The measurement array was asymmetric and concentrated on the west side of the pass. Previous analyses [Hench et al., 2008; Herdman, 2012] showed that the flows are approximately symmetric about the pass. The thermistor string and ADCP in the bay (Station $B$ ) were deployed off the center axis on the west side of the bay, and in the reef pass (Station P) instruments were deployed adjacent to a channel marker, both to avoid being damaged by large ship traffic.

A meteorological (met) station was installed on the western shore of the bay and measured wind velocity, air temperature, relative humidity, and rainfall, as well as incoming and outgoing radiation (measured over the water). Wind speed and direction were measured with an accuracy of $0.3 \mathrm{~m} \mathrm{~s}^{-1}$ or $1 \%$ in the wind speed, and

\begin{tabular}{|c|c|c|c|c|c|}
\hline Station (Depth) & Instrument Depth & Instrument & Sampling & Start Date & End Date \\
\hline R1 (2 m) & $2 \mathrm{~m}$ & $2 \mathrm{MHz}$ ADP & $\begin{array}{l}1 \mathrm{~min} \text { profiles, } 10 \mathrm{~cm} \text { bins waves: } \\
2 \mathrm{~Hz} \text { burst every hour for } 17 \mathrm{~min}\end{array}$ & 8 Dec 2006 & 16 Feb 2007 \\
\hline \multirow[t]{2}{*}{$\mathrm{R} 2(2.5 \mathrm{~m})$} & $2.5 \mathrm{~m}$ & $2 \mathrm{MHz}$ ADP & $\begin{array}{l}1 \mathrm{~min} \text { profiles, } 10 \mathrm{~cm} \text { bins waves: } \\
2 \mathrm{~Hz} \text { burst every hour for } 17 \mathrm{~min}\end{array}$ & 8 Dec 2006 & 9 Feb 2007 \\
\hline & $2.3 \mathrm{~m}$ & SBE-37 CTD & 1 sample/min & 11 Dec 2006 & 22 Feb 2007 \\
\hline R3 (3 m) & $3 \mathrm{~m}$ & $2 \mathrm{MHz}$ ADP & $\begin{array}{l}1 \mathrm{~min} \text { profiles, } 10 \mathrm{~cm} \text { bins waves: } \\
2 \mathrm{~Hz} \text { burst every hour for } 17 \mathrm{~min}\end{array}$ & 8 Dec 2006 & 8 Feb 2007 \\
\hline$B(30 \mathrm{~m})$ & $\begin{array}{c}30 \mathrm{~m} \\
5-15 \mathrm{~m} \\
\text { (at } 1 \mathrm{~m} \mathrm{spacing} \text { ) } \\
17-29 \mathrm{~m} \\
\text { (at } 2 \mathrm{~m} \text { spacing) }\end{array}$ & $\begin{array}{c}600 \mathrm{kHz} \text { ADCP } \\
\text { SBE-39 T }\end{array}$ & $\begin{array}{l}1 \text { ensemble/min } 60 \text { pings/ens } 0.5 \mathrm{~m} \text { bins } \\
2 \text { samples/min }\end{array}$ & $\begin{array}{l}14 \text { Dec } 2006 \\
15 \text { Dec } 2006\end{array}$ & $\begin{array}{l}21 \text { Feb } 2007 \\
21 \text { Feb } 2007\end{array}$ \\
\hline \multirow[t]{2}{*}{$P(43 \mathrm{~m})$} & $\begin{array}{c}42 \mathrm{~m} \\
6,10,21,26,43 \mathrm{~m}\end{array}$ & $\begin{array}{c}600 \mathrm{kHz} \text { ADCP } \\
\text { SBE-37 CTD (3) } \\
\text { SBE-16+ CTD (2) }\end{array}$ & $\begin{array}{l}1 \text { ensemble/min } 20 \text { pings/ens } 2 \mathrm{~m} \text { bins } \\
1 \text { sample/min }\end{array}$ & $\begin{array}{l}6 \text { Dec } 2006 \\
11 \text { Dec } 2006\end{array}$ & $\begin{array}{l}26 \text { Feb } 2007 \\
22 \text { Feb } 2007\end{array}$ \\
\hline & $30,35,42 \mathrm{~m}$ & SBE-39 T & 1 sample/2 $\min$ & 11 Dec 2006 & 22 Feb 2007 \\
\hline$C(15 \mathrm{~m})$ & $15 \mathrm{~m}$ & $1200 \mathrm{kHz}$ ADCP & 1 ensemble/min 60 pings/ens $0.5 \mathrm{~m}$ bins & 14 Dec 2006 & 21 Feb 2007 \\
\hline
\end{tabular}

${ }^{\text {a }}$ Station names correspond to labels in Figure 1. 
$3^{\circ}$ in direction. Incoming long wave and outgoing short wave radiation were measured with upward and downward-facing pyranometer and pyrgeometer pair (Kipp and Zonen CNR1). These measurements yielded shortwave albedo and net longwave radiation, with an expected accuracy for total daily average radiation of $10 \%$ or about $20 \mathrm{~W} \mathrm{~m}^{-2}$. All meteorological sensors were connected to a Campbell Scientific CR1000 data logger that recorded 5 min averages. Local wind measurements were supplemented by measurements from Météo France at the airport in Faa'a, Tahiti (20 km south east of the bay), because we found that the winds within the bay (and recorded by the met station) were different than those at the more exposed reef stations, based on short-term observations of wind using a handheld anemometer from the fore reef.

\section{Observations: Canonical Day}

In this analysis, we considered a "canonical day" by phase averaging all time series measurements together (for Station C this was only summer 2006-2007 and for the met station only segments of summer 2008-2009; all other locations include two summers). This served to isolate variations associated with the diurnal cycles of surface heat flux and the semidiurnal tide from the wave-driven circulation, which varies on longer duration synoptic time scales associated with remote swell events [Hench et al., 2008]. Since the wave-driven circulation varies over longer time scales, within a canonical day, the average wave-driven flow can be considered as steady. Tides also modify the wave-driven circulation, but given that the primary semidiurnal tide at this site is the $S_{2}$ constituent (period $12.00 \mathrm{~h}$ ) and thus nearly phase locked to time of day [Hench et al., 2008] astronomical tides effect each day similarly during the period that has been phase averaged. The time periods that we have averaged together experienced very similar wave and atmospheric forcing. The average temperature at R2 during both deployments was $28.8^{\circ} \mathrm{C}$ with a standard deviation of $0.5^{\circ} \mathrm{C}$ during the first summer and a smaller standard deviation of $0.3^{\circ} \mathrm{C}$ in the summer of 2008-2009. The velocities in the back reef were also similar with an average speed of $0.15 \mathrm{~m} \mathrm{~s}^{-1}$ and standard deviations of $0.07 \mathrm{~m} \mathrm{~s}^{-1}$ during both summers. Given the similarity of conditions, we believe it is reasonable to represent these data from different years in an averaged sense, i.e., the canonical day, to describe what typically occurs during the austral summer.

In order to understand the thermal balance in the reef system as a whole, over the course of a canonical day, we first examine the thermal balance in each section: reef, pass, and bay. To compute the thermal balance, we start with a two-dimensional description of heat conservation:

$$
\rho c_{p}\left(\frac{\partial T}{\partial t}+\frac{\partial(U T)}{\partial x}+\frac{\partial(W T)}{\partial z}\right)=\frac{\partial q}{\partial z}
$$

where $\rho$ is density, $c_{p}$ is the specific heat of water, $T$ is temperature, $q$ represents the sum of all heat sources and sinks as well as vertical turbulent mixing, $U$ corresponds to the velocity in the along-bay $(x)$ direction, and $W$ and $z$ are vertical velocity and direction, respectively. Integrating (1) over the water column and dividing by total depth $(d)$ gives

\begin{tabular}{|c|c|c|c|c|c|}
\hline $\begin{array}{l}\text { Station } \\
\text { (Depth) }\end{array}$ & Instrument Depth & Instrument & Sampling & Start Date & End Date \\
\hline \multirow[t]{2}{*}{$\mathrm{R} 1(2 \mathrm{~m})$} & $2 \mathrm{~m}$ & $2 \mathrm{MHz}$ ADP & 1 min profiles, $10 \mathrm{~cm}$ binswaves: & 1 Dec 2008 & 16 Jan 2009 \\
\hline & & & $2 \mathrm{~Hz}$ every hour for $17 \mathrm{~min}$ & 7 Feb 2009 & 21 Feb 2009 \\
\hline \multirow[t]{3}{*}{$\mathrm{R} 2(2.5 \mathrm{~m})$} & $2.5 \mathrm{~m}$ & $2 \mathrm{MHz}$ ADP & 1 min profiles, $10 \mathrm{~cm}$ bins waves: & 1 Dec 2008 & 1 Feb 2009 \\
\hline & & & $2 \mathrm{~Hz}$ every hour for $17 \mathrm{~min}$ & 7 Feb 2009 & 21 Feb 2009 \\
\hline & 2.3 & SBE 37 & 1 sample/2 min & 12 Dec 2008 & 21 Feb 2009 \\
\hline \multirow[t]{2}{*}{ R3 (3 m) } & $3 \mathrm{~m}$ & $2 \mathrm{MHz}$ ADP & 1 min profiles, $10 \mathrm{~cm}$ bins waves: & 1 Dec 2008 & 18 Jan 2009 \\
\hline & & & $2 \mathrm{~Hz}$ every hour for $17 \mathrm{~min}$ & 7 Feb 2009 & 21 Feb 2009 \\
\hline \multirow[t]{2}{*}{$B(30 \mathrm{~m})$} & $30 \mathrm{~m}$ & $600 \mathrm{kHz}$ ADCP & 1 ensemble/min 60 pings/ens $0.5 \mathrm{~m}$ bins & 14 Dec 2008 & 3 Feb 2009 \\
\hline & $6,29 \mathrm{~m}$ & SBE-37 & 1 sample/3 $\min$ & 15 Dec 2008 & 3 Feb 2009 \\
\hline \multirow[t]{2}{*}{$P(43 \mathrm{~m})$} & $42 \mathrm{~m}$ & $600 \mathrm{KHz}$ ADCP & 1 ensemble/min 20 pings/ens $2 \mathrm{~m}$ bins & 16 Aug 2008 & 5 Feb 2009 \\
\hline & $\begin{array}{l}1,6,9,20,27 \\
35,32,43 \mathrm{~m}\end{array}$ & $\begin{array}{l}\text { SBE-37 (5) SBE-16+ (2) } \\
\text { SBE } 19 \text { (1) }\end{array}$ & 1 sample/3 min & 5 Dec 2008 & 20 Feb 2009 \\
\hline \multirow[t]{2}{*}{ Met } & & Anemometer Temperature & 1 sample/5 min & 7 Dec 2008 & 18 Dec 2008 \\
\hline & & $\begin{array}{l}\text { Humidity Radiometer } \\
\text { Rainfall Gage }\end{array}$ & & 5 Feb 2009 & 18 Feb 2009 \\
\hline
\end{tabular}

${ }^{\text {a }}$ Station names correspond to the labels in Figure 1. 


$$
\frac{\partial\langle T\rangle}{\partial t}+\frac{\partial\langle U\rangle\langle T\rangle}{\partial x}+\frac{\partial\left\langle U^{\prime} T^{\prime}\right\rangle}{\partial x}=\frac{H}{\rho c_{p} d}
$$

where \langle\rangle indicates depth-averaged quantities and primes indicate deviations from depth averages. The third term in (1), representing the vertical divergence of heat, is zero after integration, invoking the common assumption that the vertical velocity is zero at the bottom and at the surface. We assumed no heat fluxes from the seafloor and that the surface heat flux, $H$, is the sum of short wave radiation $\left(H_{S W}\right)$, long wave radiation $\left(H_{L W}\right)$, and the sensible $\left(H_{S}\right)$ and latent heat $\left(H_{L}\right)$ fluxes

$$
H=H_{S W}+H_{L W}+H_{S}+H_{L}
$$

$H>0$ implies flux into the water column. In the following analysis, we use the phase-averaged values for surface heat fluxes, water temperatures, and velocities to examine the importance of each term in the thermal balance over the canonical day.

\subsection{Canonical Day of Meteorological Conditions}

We first consider the canonical day of atmospheric forcing, as the heat fluxes in (3) all depend on atmospheric conditions. Direct measurements of long and short wave radiation along with variables necessary to estimate sensible and latent heat flux using bulk formulae [Pawlowicz et al., 2001] were made during the 2008-2009 experiments (Figures 2 and 3). Winds used to compute latent and sensible heat fluxes were

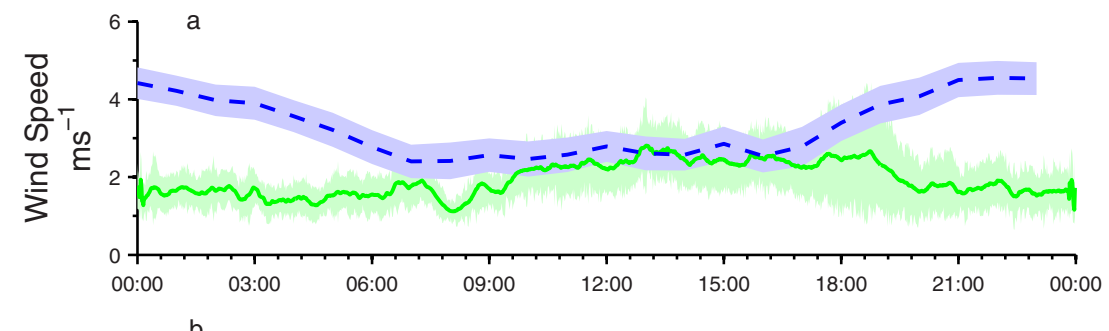
drawn from two different sources (Figure 2). Winds measured by the met package deployed near Station B characterized the more sheltered environ-

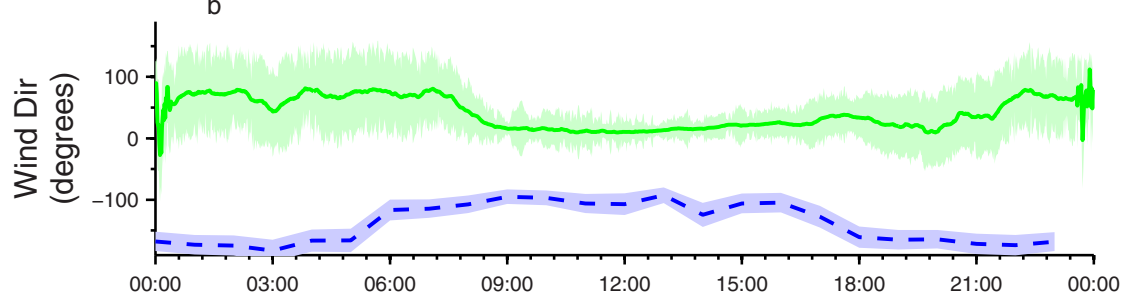
ment of the bay, while winds measured at Faa'a better represent winds that act on the back reef and open ocean. For most daylight

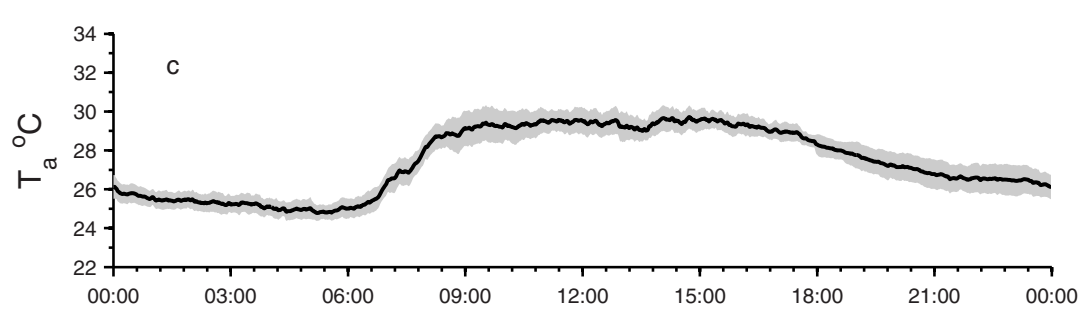
hours, the phaseaveraged wind over the bay and the reef were similar in magnitude. In the early afternoon, the reef winds picked up

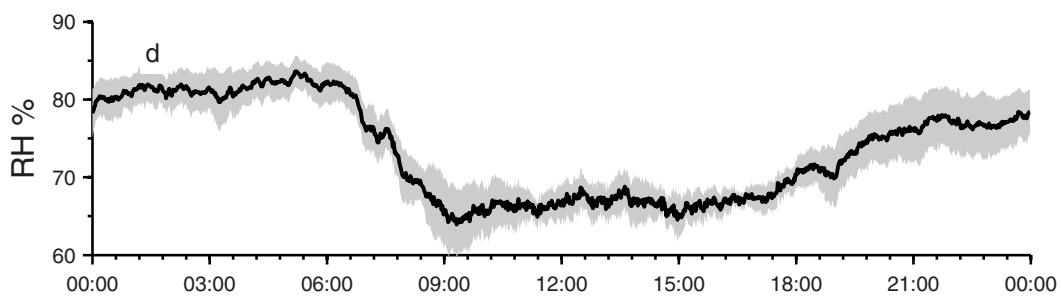
and increased to a maximum mean speed of $4.5 \mathrm{~m}$ $\mathrm{s}^{-1}$ around midnight. The bay winds measured by the met station did not have a

Figure 2. Phase-averaged daily meteorological conditions. (a) Wind speed; (b) wind direction (direction is where wind comes from); (c) air temperature; and (d) relative humidity. In Figures 2a and 2b, dashed blue lines are winds measured at Faa'a airport, and solid green lines are from met station at Station B. Shading indicates $95 \%$ confidence intervals about the mean.

strong diurnal sig nal, which was evident from 

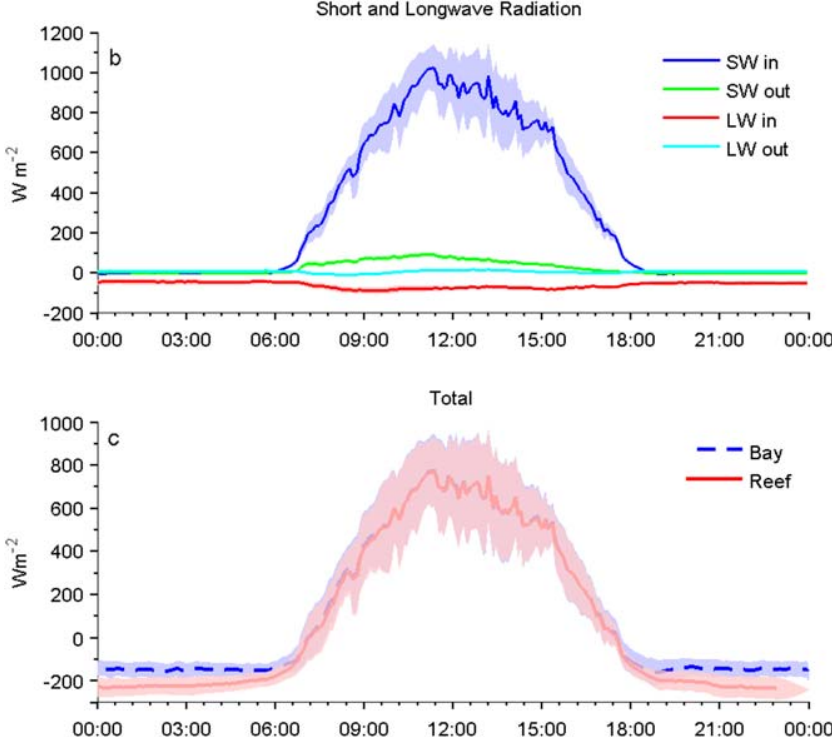

Figure 3. Daily average surface heat fluxes measured by met station adjacent to Station B. (a) Sensible and latent heat fluxes for reef (R) and bay (B) stations; (b) short wave and long wave radiation; (c) total heat flux for back reef (solid) and bay (dashed). Shading indicates $95 \%$ confidence intervals about the mean.

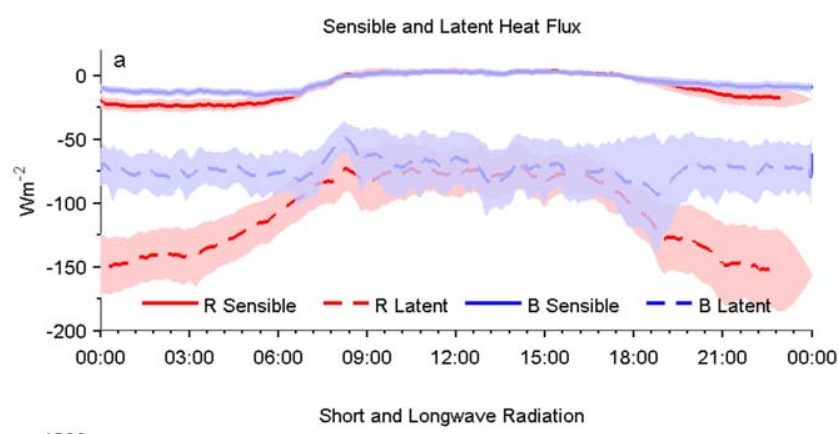

spectral analysis of the wind speed and direction time series (not shown). Surface air temperature varied between 25 and $30^{\circ} \mathrm{C}$ and followed a diurnal pattern of solar heating during the day and cooling at night (Figure $2 \mathrm{c}$ ). Relative humidity varied between $63 \%$ and $84 \%$ (Figure 2d). A large rainfall event occurred during the 2006-2007 deployment; however, rainfall was below detection limits during 2008-2009 (data not shown). A more detailed discussion of the role freshwater input on the system is in the Appendix A, where we show that freshwater is not usually of primary importance in creating density gradients.

Throughout the experiment, incoming short wave radiation was much larger than long wave radiation and albedo ( 0.1) was small (Figure $3 b$ ). At the peak time of day for short wave radiation, the $95 \%$ confidence level about the mean is $\pm 200 \mathrm{~W} \mathrm{~m}^{-2}$, indicating a large amount of variability in the incident heating rate. The source of variability was likely the changing nature of cloud cover, which is common to the mountainous terrain of Moorea during austral summer. The spatial variability in wind speed translates to a net daily average difference between the reef and bay of $50 \mathrm{~W} \mathrm{~m}^{-2}$ (Figure 3a). These surface heat fluxes are used in the following calculation of heat balance in the bay and reef.

\subsection{Canonical Day of Circulation in the Bay}

To calculate the thermal budget in the bay using equation (2), we first constructed a canonical day of water temperature and velocity. The data show a clear diurnal pattern in both (Figure 4). For the first half of the day (midnight to noon), there was a vertically sheared exchange flow along the axis of the bay, with the upper water column flowing out toward the pass and the lower water column flowing in toward the bay (Figure 4b). During that time, bottom temperature decreased and the amount of cold water in the bay increased (Figure 4a). There was an afternoon transition and by 15:00, bottom flow reversed and was directed toward the reef pass (seaward). During the beginning of the outflow period, the cold bottom layer thinned quickly and the temperature changed little until 18:00. The peak temperature at the surface occurred at 21:00 (3 h after sunset) which is considerably later than what would be predicted if temperature changes were only due to local input of solar radiation. At all depths, the temperature changed at roughly the same rate, maintaining a constant level of stratification with the bottom consistently $0.3^{\circ}$ cooler than the surface.

We can approximately model the bay as a two-layer system divided at middepth. The two-layer model seems appropriate, as even when both layers were briefly flowing in the same direction (seaward in the early evening; Figure 4b), there was a quiescent transition at middepth dividing the upper and lower layers. The fact that there was no change in free-surface height observed in the bay during this positive depth-averaged flow implies that there was a lateral circulation cell in the latter half of the day with water flowing into the bay along the east side (where no measurements are available). The across-bay velocity shows evidence of a twolayer across-bay circulation that was strongest around canonical hour 15:00 (Figure 4c). In the following 

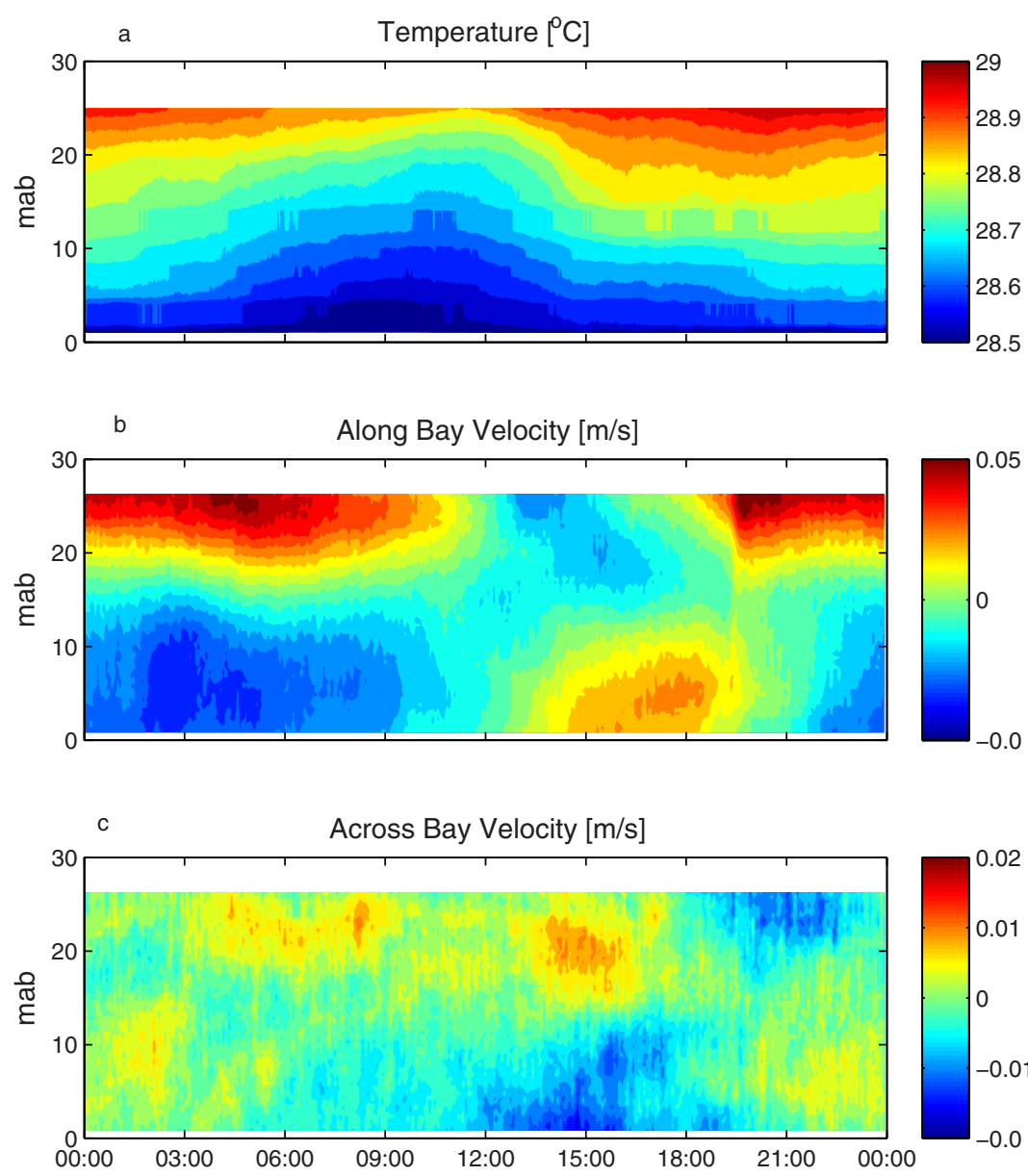

Figure 4. Canonical day (phase-averaged) data for Station B in bay derived from all full day records during the 2006-2007 deployment. (a) Temperature; (b) along-bay (major axis) velocity where negative velocities are toward the closed end of the bay; and (c) across-bay (minor axis) velocity where positive values are toward the western side of the bay. calculations for thermal balance, we make the reasonable assumption that the depth-averaged flow was actually close to zero when averaged across the bay. In support of this assumption, a spectral analysis of the depthaveraged velocity at Station B [Herdman, 2012] did not show any peaks near or above the diurnal frequency, indicating we do not expect a regular contribution from depth-averaged velocity over the canonical day. There are some lower-frequency signals that are associated with lowfrequency oscillations in bay water level, which do contribute to the canonical day average. However, the depth-averaged velocity was never statistically different from zero.

\subsubsection{Thermal Balance in Bay}

Subject to the assumption that there is no variability across the bay in either temperature or velocity, the heat balance in the bay can be estimated from our measurements as follows. Integrating (2) from the bay measurement station (B) to the closed southern end of the bay, and using the fact that there is no horizontal flux at the end of the bay gives

$$
\frac{1}{L} \frac{\partial}{\partial t} \int_{-L}^{0}\langle T\rangle d x=\frac{H}{\rho c_{p} d}-\frac{1}{L}\langle U\rangle\langle T\rangle-\frac{1}{L}\left\langle U^{\prime} T^{\prime}\right\rangle
$$

where $L$ is the length of the bay. The depth-averaged velocity (in the second term on the right) is close to zero, whereas the advective flux contribution to (4) from $\left\langle U^{\prime} T^{\prime}\right\rangle$ should be substantial. Note that (4) is exact, but, given only one measurement station, the integral on the left side was estimated by assuming that temperature only varies with height, and not along the axis of the bay. Thus, we have approximately:

$$
\frac{d}{d t}\langle T\rangle_{B} \approx \frac{H}{\rho c_{p} d}-\frac{1}{L}\left\langle U^{\prime} T^{\prime}\right\rangle_{B}
$$

To understand the relative importance of local to advective contributions to temperature variability in the bay, we compared the time rate of change in temperature (LHS of (5)), to the surface heat fluxes that make up $H$ and the sheared advection term (RHS of (5)). The data suggest that observed temperature changes in the bay are associated with both surface heat fluxes and advection (Figure 5a). Advection primarily acts to shift 

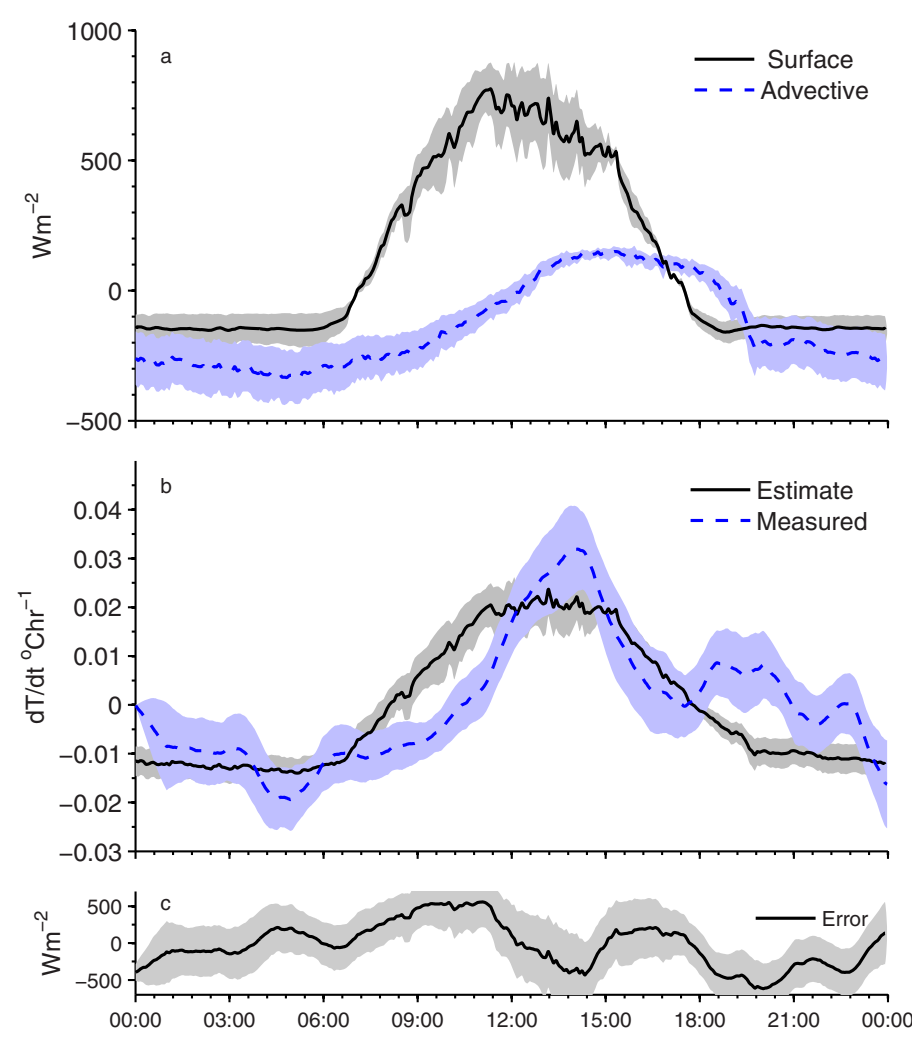

Figure 5. Thermal balance in bay. (a) Advection and surface heat fluxes; (b) depthaveraged temperature rate of change estimated from summing terms shown in Figure 5 a (solid black) and measured rate of change from depth-averaged temperature (dashed blue); (c) error shown as difference between estimated and measured (Figure 5b). Shading indicates $95 \%$ confidence levels about the mean. the peak temperature to later in the day than would occur without the observed shear flows, and transports the heat input from surface heat fluxes out of the bay. The system appears to be near thermal equilibrium, since there is virtually no net change in the depth-averaged temperature over the course of a canonical day.

Comparison of the proposed heat balance (RHS of equation (5)), to the measured time rate of change of depth-averaged temperature at site B (LHS of equation (5)) allows for evaluation of the accuracy of our simple model. From canonical hours 08:00 to 12:00, the observed rate of temperature change is less than what would be inferred from calculated surface heat fluxes and advection. From 12:00 to 15:00, the average observed rate of temperature change has a greater peak than the estimate, although the $95 \%$ confidence intervals indicate these values are not significantly different (Figure 5b). Thus, despite the assumption of no lateral vari-
can be captured with a simple ability, the data suggest that the major dynamics of the thermal balance can be captured with a simple one-dimensional model (Figure 5).

\subsubsection{Momentum Balance in Bay}

Given the important role of advection in determining bay temperature, it is useful to consider the dynamics responsible for this diurnal exchange flow. In order to do this, we estimated the terms in a simplified momentum balance. We divided the bay into two vertical layers and calculated the momentum balance for each layer. Assuming no gradients in the lateral $(y)$ direction, the equation for each layer can be written as

$$
\rho\left(\frac{\partial u_{i}}{\partial t}+u_{i} \frac{\partial u_{i}}{\partial x}\right)=-g \rho \frac{\partial \eta}{\partial x}-\frac{\partial \Pi_{i}}{\partial x}+\frac{\tau_{i}}{h}
$$

where $u_{i}$ is the average velocity for the ith layer and $\tau_{i}$ is the sum of the stresses on the ith layer. In the surface layer, $\tau_{i}$ includes wind stress and interfacial shear stress, and on the bottom layer it includes the interfacial shear stress and bottom stress. $\Pi$ is the baroclinic component of the pressure and the average gradient for each of the two layers can be expressed as

$$
\begin{aligned}
& \frac{\partial \Pi_{1}}{\partial x}=\frac{1}{2} g h_{1} \frac{\partial \rho_{1}}{\partial x} \\
& \frac{\partial \Pi_{2}}{\partial x}=g h_{1} \frac{\partial \rho_{1}}{\partial x}+\frac{1}{2} g h_{2} \frac{\partial \rho_{2}}{\partial x}
\end{aligned}
$$

where $h$ and $\rho$ are the height and density of the layer indicated by subscript, although in this case the layers are assumed to be equal depth, i.e., $h_{1}=h_{2}$. The Coriolis term was not included in this along-bay balance as it can be shown to be much smaller than the terms included in (6). Adding the equations for each layer together gives 


$$
\frac{\partial\left(u_{1}+u_{2}\right)}{\partial t}+u_{1} \frac{\partial u_{1}}{\partial x}+u_{2} \frac{\partial u_{2}}{\partial x}=-2 g \frac{\partial \eta}{\partial x}-\frac{1}{\rho} \frac{\partial \Pi_{1}}{\partial x}-\frac{1}{\rho} \frac{\partial \Pi_{2}}{\partial x}+\frac{\tau_{w}}{\rho h}+\frac{\tau_{b}}{\rho h}
$$

Since the interfacial stress is equal and opposite between the layers, the term disappears in the sum, allowing us to solve the equations for each layer. Since net flow is small (not significantly different from zero) and slowly varying, its derivative is also small and $\partial\left(u_{1}+u_{2}\right) / \partial t \approx 0$. These simplifications permit a solution for the barotropic pressure gradient in terms of the two baroclinic gradients averaged over each layer, the wind stress, the bottom stress, and the advective acceleration. The bottom stress was estimated as $\tau_{b} \approx C_{d} U_{b}\left|U_{b}\right|$, using a bottom drag coefficient of 0.0025 [e.g., Sternberg, 1968]. This term was found to be 2 orders of magnitude smaller than the leading order terms and therefore neglected in our calculations. We calculated the baroclinic pressure gradient in each layer using the density gradient between Stations B and P. The wind stress was computed using

$$
\begin{aligned}
\tau_{w} & =\rho_{\text {air }} C_{d} U_{w}^{2} \\
1000 \times C_{d} & =0.29+\frac{3.1}{U_{w}}+\frac{7.7}{U_{w}^{2}}
\end{aligned}
$$

which relates wind stress to wind speed $\left(U_{w}\right)$, which was measured adjacent to Station B [Yelland and Taylor, 1996]. The average wind stress term was found to be $1 \times 10^{-6} \mathrm{~m} \mathrm{~s}^{-2}$ and never exceeded the average by more than $20 \%$. The advective acceleration was estimated with the velocity measured at Station $\mathrm{B}$, and the gradient was found by assuming that the velocity goes to zero for each layer at the closed end of the bay. This term was much smaller than all of the other terms shown (Figure 6). Summing these terms gives an estimate of the barotropic pressure gradient (Figure 6). The barotropic pressure gradient was the only term

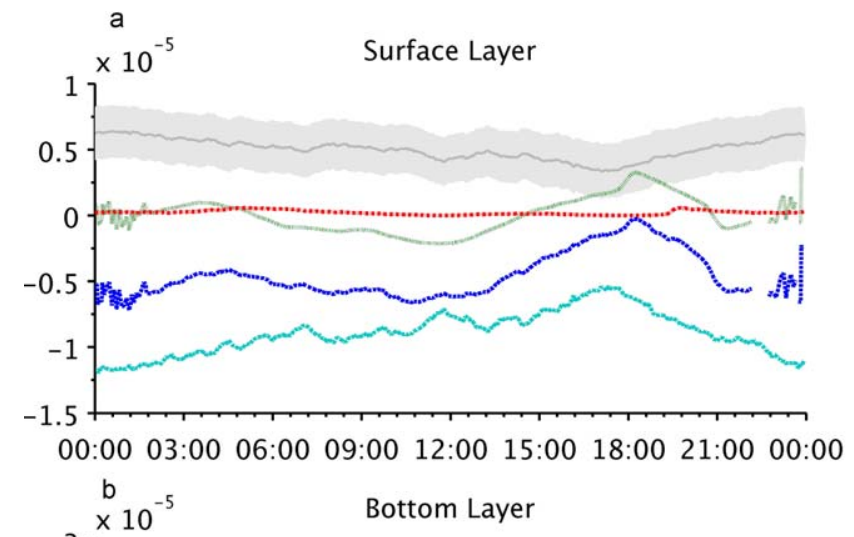

large enough to balance the baroclinic pressure gradient, and it was persistently negative, indicating, at the maximum, that the free-surface water level at the closed end of the bay was about $3 \mathrm{~cm}$ higher than the open ocean end. This gradient in freesurface height varies in magnitude with the baroclinic pressure gradient. While we expect the presence of a free-surface gradient associated with the waves that drives flow out of the pass [Hench et al., 2008; Monismith, 2014], this freesurface gradient would be expected to vary with wavedriven forcing. Since wavedriven forcing does not have a diurnal signal, it appears that the diurnal variation in the free-surface gradient in the bay is a response to the baroclinic gradient.

Returning to the first-layer equation (6), it follows that any

Figure 6. Momentum balance in bay. Legend shows terms of equation (6) in the (a) surface layer and (b) bottom layer. Shading indicates the $95 \%$ confidence interval around the baroclinic term. The confidence intervals on the other terms are much smaller and are not included. Note Figures $6 \mathrm{a}$ and $6 \mathrm{~b}$ have different $y$-axis limits. Although wind stress (for the surface layer) is included in the calculations, given its negligible contribution it is not shown in the figure for clarity. difference between the baroclinic pressure gradient and the other terms (advection, barotropic pressure gradient, 
and wind) would result in acceleration of the flow and losses to interfacial shear stress. Since we have measurements of the velocity acceleration in each layer we can find the required shear stress necessary to close the balance in the top layer. These terms and their evolution through the canonical day are in Figure 6a. A linear fit of the shear stress term to the parameterization of the stress as $\tau_{l}=C_{I} \Delta U|\Delta U|$, where $\Delta U$ is the difference between the velocity layers, resulted in a stress coefficient $C_{I}$ of 0.01 , which is twice the values found in the estuarine literature [Arita and Jirka, 1987]. This difference can be attributed to the comparatively weak stratification in this system, allowing momentum to be more easily exchanged across the distinct velocity layers. The sign of the interfacial shear stress indicates a persistent momentum transfer from the surface layer to the bottom layer. The stress approached zero when there was no velocity difference between the layers, which is consistent with the physics even though the stress is inferred from the other terms.

The momentum balance in the bottom layer can be solved by applying an equal and opposite shear stress to that calculated for the surface layer (Figure 6b). The error can then be estimated by finding the difference between the sum of these terms and zero, i.e., what is necessary to close the balance for the lower layer. This error is small relative to the other terms $\left(O\left(10^{-6}\right)\right)$ included in the momentum balance; in fact, this error is less than the variability in the canonical average of the baroclinic gradient. Overall, the primary momentum balance in the lower layer was between the baroclinic and barotropic pressure gradients with the interfacial stress and acceleration terms being of secondary importance.

Although rotation is not important in the along-bay balance we calculated here, rotation may play a role in the lateral circulation. The role of rotation in lateral circulation can be assessed by comparing the internal Rossby radius $\left(R_{i}\right)$ to the width of the bay. $R_{i}$ is given as $C / f$, where $C$ is the first mode internal wave speed ( $~ 0.03 \mathrm{~m} \mathrm{~s}^{-1}$ based on a $0.3^{\circ} \mathrm{C}$ temperature difference and a half depth of $15 \mathrm{~m}$ ) and $f=-4.4 \times 10^{-5} \mathrm{~s}^{-1}$ is the local Coriolis parameter. These give $R_{i}$ of about $600 \mathrm{~m}$ compared to a geometric width of $1 \mathrm{~km}$. Rotation could support a deflection of the interface across the bay, which would lead to asymmetries in the in and out flow across the bay. It seems likely that rotation plays a role in lateral circulation within the bay and might explain the strong across-bay velocities in the afternoon and also might contribute to the under prediction of the time rate of change of temperature at that time of day (Figure 5b). Unfortunately, this data set does not allow us to address these cross-bay asymmetries in detail.

\subsection{Canonical Day in the Back Reef}

The persistent and positive baroclinic pressure gradient responsible for driving the exchange flow in the bay is a result of the bay being consistently warmer than the pass. This requires consideration of the other parts of the reef to understand how this temperature gradient is maintained. In this section we consider the back reef, the shallow area of reef between the reef crest and the island. The depth-averaged velocity in the back reef (Station R2) was $0.15 \mathrm{~m} \mathrm{~s}^{-1}$ and was modulated by variations in water level (Figure 7a). The largest

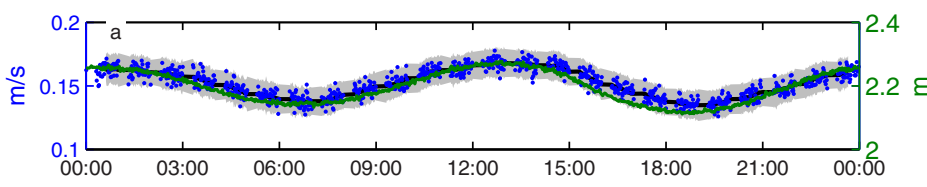
component of the tide, the semidiurnal $S_{2}$ component, is apparent in the velocity signal. The peak velocity was concurrent with high tides around

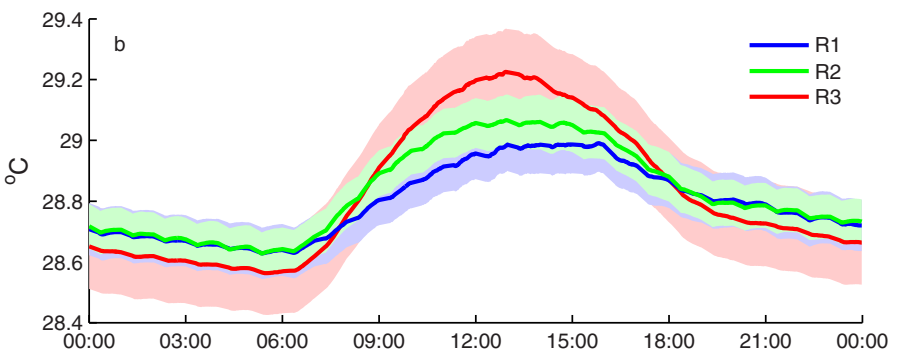
01:00 and at 13:00. The wavedriven flow on the back reef increases with a higher water level at the reef crest [Hearn, 1999; Callaghan et al., 2006]. If the velocity variations were from the volume flux associated with astronomical tides, the water level and currents

Figure 7. Canonical day in the back reef. (a) Velocity and free-surface height measured at Station R2. Blue dots are depth-averaged speeds and the black line represents $1 \mathrm{~h}$ average using a sliding window (scale on left axis). The green line and right axis correspond to the free-surface height. (b) Temperature measured at reef Stations R1 (blue), R2 (green), and R3 (red). Shading indicates $95 \%$ confidence intervals about mean. would be out of phase; since velocity and water level were in phase, it is likely because the velocity was wave driven but 
affected by tidal elevation at the reef crest. In contrast to temperature records and despite phase averaging over the two summer records, there remained substantial variability in the phase-averaged velocity in the back reef, variability that is due to the episodic nature of the wave-driven flow from discrete swell events.

Although the velocity is highly variable, the temperature in the back reef exhibits a consistent diurnal temperature signal. Stations R1, R2, and R3 exhibited very similar trends in temperature, with minimum temperatures at 06:00 that increased over the course of the day and peaked in the afternoon. The peak occurred later in the day closer to the reef crest. These patterns resemble what one would expect as the result of solar heating and are similar to observations on other reefs with a strong diurnal temperature signature [Coles, 1997; Smith, 2001; Davis et al., 2011; Gramer et al., 2012; Zhang et al., 2013; Molina et al., 2014].

The observed spatial temperature gradients along the direction of flow reflect the periods of cooling and heating on the back reef. From about 19:00 to 06:00, net cooling occurred between R2 and R3, which matched the negative sign of the surface heat flux (Figures 7 and 8). The opposite was true from 06:00 to 19:00. The water reaching R3 has experienced the surface heat flux over a shallow depth for a longer time period resulting in a greater daily temperature range. This gradient in temperature is important for understanding the thermal balance at R2. Since the back reef is shallower than the offshore surface mixed layer, water in the back reef heats more rapidly during the day and cools more rapidly at night. Thus, the onshore flow brings cooler water to the back reef during the day, and warmer water at night.

To calculate the thermal balance in the back reef, we again start with equation (2). However, since the back reef area is shallow, there is no significant variation in temperature and velocity with depth, and we also assumed no depth-averaged velocity gradient across the reef flat which leaves us with the equation:

$$
\frac{\partial\langle T\rangle}{\partial t}+\langle U\rangle \frac{\partial\langle T\rangle}{\partial x}=\frac{H}{\rho c_{p} d}
$$

To evaluate this balance, we consider the rate of depth-averaged temperature change at $\mathrm{R} 2$, so $\langle T\rangle,\langle U\rangle$ are the temperature and depth-averaged velocity measurement at R2 (shown in Figure 7a) and the spatial temperature gradient is based on the temperature difference between R2 and R3. The terms of equation (10) are shown in Figure 8, demonstrating that advection was comparable in magnitude and was out of phase with solar heating on the back reef.
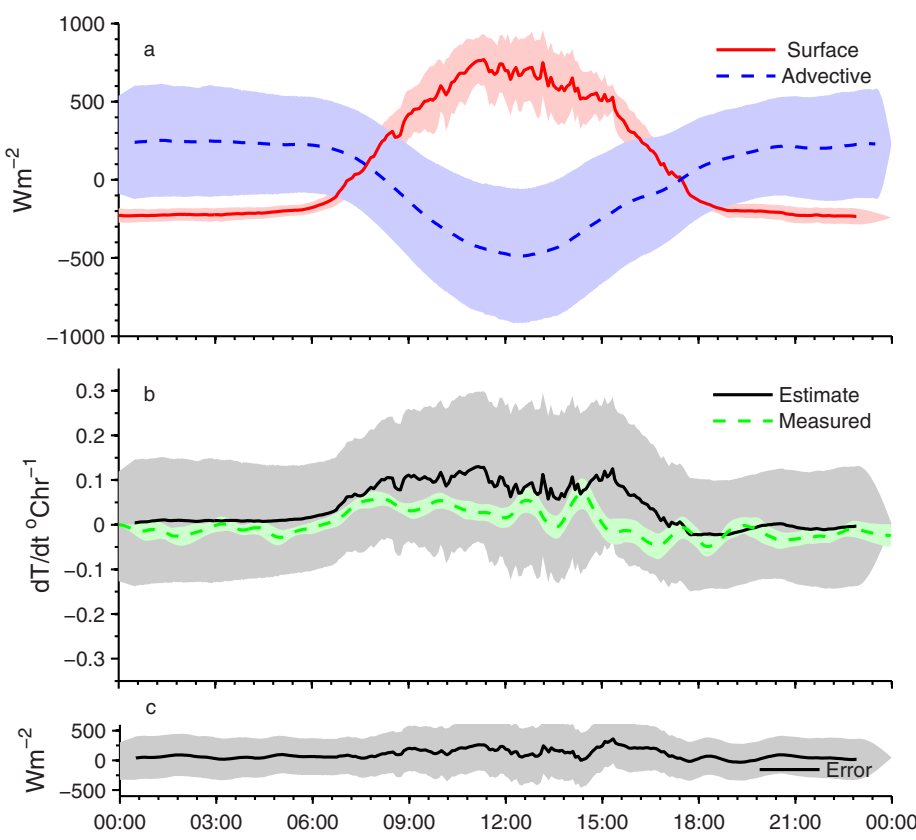

Figure 8. Estimate of the thermal balance for the back reef at Station R2. (a) Total surface heat fluxes, and calculations of advection; (b) estimated rate of temperature change, calculated by summing terms in Figure $8 \mathrm{a}$ (solid black) and the measured rate of temperature change (dashed green); (c) error between estimated and measured temperature change shown in Figure 8b. Shading indicates $95 \%$ confidence intervals about the mean.
On the back reef, estimated and measured rates of phaseaveraged temperature change both showed high-frequency variability (Figure $8 b$ ). Due to the shallowness of the back reef, the estimate of rate of temperature change was more sensitive to variability in radiation. Since surface radiation was actually observed over a shallow section of the bay, it is possible that differences in bottom reflectivity [Maritorena et al., 1994; Wells et al., 2012] between the two sites could bias the measurement. At the location of our measurement (Station B), outgoing short wave radiation ranged from 5 to $16 \%$ of the incoming radiation which is consistent with other measurements in similar locations [Payne, 1972; 
Maritorena et al., 1994; Zhang et al., 2013]. Zhang et al. [2013] also found that spatial variation in total albedo was not significant, which gives us some confidence in using this radiation measurement reef wide. Even if there was an error in the measured reflectance, it is substantially smaller than the large variation in advection. In calculating the advection term, we found the variability in the phase-averaged value was the same magnitude as the average itself. The variability, shown by the confidence intervals of the advection term, is so large because advection depends on the gradient of temperature, and the variation in the gradient is the same order of magnitude as the gradient itself. Since the uncertainties add in quadrature, this creates an uncertainty in net advective flux that is also order 1. There is also the inherent error in using single station measurements, which given the complex topography of the reef have some flow divergence between them. However, what is actually being calculated here is a flux of temperature, and the flow per unit width of reef is remarkably consistent along this transect [Monismith et al., 2013]. The measured and predicted temperature changes approximately agree prior to 12:00 but increasingly diverge around 15:00. Although the predicted temperature change was quite variable, it appears to capture key features of the thermal heat balance on the back reef: advection coupled with the diurnal heating and cooling.

\subsection{Systematic Error in Heat Balance}

Given the assumptions inherent to our one-dimensional models and the use of phase-averaged data from different time periods, it is important to thoroughly consider the potential errors. In a test of bias of error in the heat balance (Figures $5 \mathrm{c}$ and $8 \mathrm{c}$ ) the residuals were not statistically different from the expected value of zero (i.e., the error is always within the $95 \%$ confidence interval of zero). Thus, there was not a consistent bias in the estimate of the temporal temperature derivative, $\partial\langle T\rangle / \partial t$, using the measured heat fluxes. However, the time series of errors in the back reef heat budget failed an adjacency test (Durbin-Watson test) for randomness, indicating that fluctuations in the error were not random [Kanji, 2006]. Unfortunately, because all the terms in the heat balance were correlated, a comparison of the single regressions between the error and the individual terms in the balance is not sufficient to identify which term contributed most to the total error. A multiple linear regression of errors in the back reef with the four dependent variables (radiation, sensible and latent heat flux, and advection) showed strong correlation $\left(R^{2}=0.93\right)$. Due to the phase averaging of observations with different offshore water temperature, wave conditions, and surface heat fluxes, there is a substantial amount of noise in the reported balances; however, there does not appear to be any systematic bias. A more complete meteorological record and measures of offshore conditions could provide a means to normalize the data to account for this effect; however, this was not possible for the present data.

In considering the errors in the bay model, the model performs much better. In the heat balance for the bay, the $95 \%$ confidence interval of the advection term was substantially smaller, in part, because only one measurement station was used in calculating this term. Since the error was not statistically different from zero, we can also assume that assumptions used to simplify the problem did not introduce bias into the estimates (Figure 5c). The errors in the bay (Station B) measurements, unlike those on the reef, were not well explained by the measurements of surface and advective heat fluxes. The multiple linear regression of errors in the lagoon heat balance with the contributing heat flux terms yields a poor fit $\left(R^{2}=0.2\right)$. Thus, any nonrandom contribution to the error in the bay heat balance is not due to our measurements, but likely related to the one-dimensional assumption that neglects lateral heat fluxes.

\subsection{Canonical Day in Reef Pass}

The last location to consider is the reef pass (Station P in Figure 1b), where water exits from the reef lagoon to the ocean. This is also the location used to calculate the temperature gradient for the baroclinic contribution to the bay momentum balance. The phase-averaged reef pass measurements exhibited two-layer flow with the zero-velocity line dividing the layers usually between 5 and $10 \mathrm{~m}$ above bottom. The daily pattern in the along-channel exchange flow (Figure 9c) had an upper layer with outflow speeds of $0.15-0.2 \mathrm{~m} \mathrm{~s}^{-1}$. The phase-averaged depth-averaged velocities show a semidiurnal signal, with local minimums in outflow at 09:00 and 21:00 and maxima at 03:00 and 15:00 (Figure 9d). This signal was out of phase with both the expected tidal flow and the velocity in the back reef. It lagged the flow in the back reef by $2 \mathrm{~h}$ and preceded the tidal flow expected from a standing wave by $1 \mathrm{~h}$. The mean advection time for wave-driven flow to reach the pass was previously estimated as $\sim 3 \mathrm{~h}$, depending on the strength of the wave-driven flow [Hench et al., 2008], so it is likely that this short lag of the reef velocity is also related to the strong forcing of 


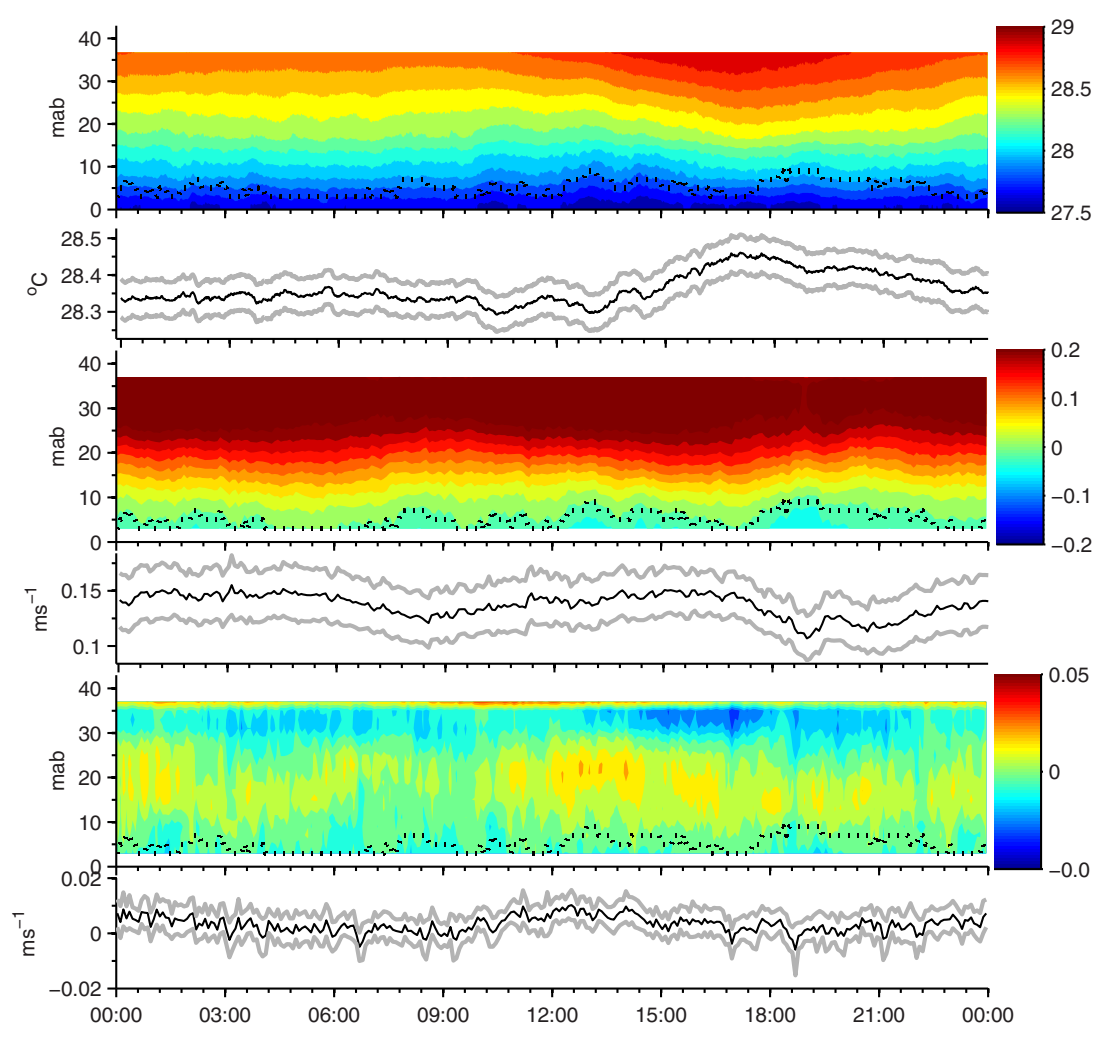

Figure 9. Canonical day in reef pass at Station P. (a) Temperature variation with depth; (b) depth-averaged temperature; (c) major axis/along pass velocity with positive being oceanward; (d) depth-averaged out of pass velocity. Gray line indicates $95 \%$ confidence interval. (e) Minor axis/across pass velocity (note smaller scale); ( $f$ ) depth-averaged across pass velocity. Black dashed line is the zero isovel in Figures 9a, $9 c$, and 9e. the wave-driven flow during the two records that were phase averaged. The lowest depthaveraged flow occurred between 18:00 and 20:00 when the exchange flow was largest. This low occurred just after the peak in surface temperature (Figure 9a). The cross-channel reef pass velocity was small and shows no trend over the day in a depth-averaged sense (Figures 9e and 9f). There was an enhanced surface and opposite middepth flow in late afternoon, near the time of maximum surface temperature.

Reef pass temperatures had a clear daily

trend with depth-averaged temperature (Figure 9b) and surface temperature both peaking at 17:00 (Figure 9a). The increase in depth-averaged temperature is because warmer water is exiting the surface of the pass. The ocean water intruding on the bottom does not have any diurnal signal in temperature; thus, the diurnal changes in pass structure associated with the strength of the baroclinic gradient and not the wave forcing are driven by the changes in temperature of the water exiting the pass. The pass bottom velocity increases during this peak surface temperature. Unfortunately, the moored temperature measurements did not have high enough vertical resolution to observe the increased depth of cold water at the same time. Along-pass shipboard CTD transect data collected during the experiment (not shown) confirmed that in the afternoon the level of cold water increased concurrently with an increase in intrusion velocity. The depth of the interface was essentially stationary between morning and early afternoon and in late afternoon moved $5 \mathrm{~m}$ closer to the surface. This bottom intrusion does not exceed the depth of the bottom of the bay, however, as the bay is no more than $30 \mathrm{~m}$ deep and the cold intrusion does not exceed $10 \mathrm{~m}$ off the bottom of the 40-50 m deep pass. For a brief period in the afternoon the temperature gradients strengthen enough to regularly enhance the baroclinic exchange flow in the pass, but not significantly enough to drive exchange to the bay.

The diurnal pattern and vertical structure in the pass helps in interpreting the momentum balance in the bay. The flow in the bay was highly dependent on the density gradient between the bay and pass, as the largest term in the momentum balance in both the surface and bottom layers was the baroclinic pressure gradient. The baroclinic pressure gradient term in the momentum balance reaches its minimum value (Figure 6) just as the surface of the pass reaches a maximum temperature, thus reducing the pass-bay temperature gradient. This indirectly links the strength of the flow in the bay to the strength of the wave-driven flow, since the wave-driven flow modifies the vertical structure of velocity and temperature in the pass [Hench et al., 2008; Herdman, 2012]. When the waves are strong, both the velocity and density profile within the pass becomes more uniform. When the waves are weak, the pass is more stratified and the surface is warmer. Since the baroclinic gradient that drives the pass exchange flow requires the bay to be warmer 
than the pass, the weak wave condition lessens the temperature/density gradient and thus reduces the strength of the exchange flow in the bay. Conversely, when the waves are stronger the exchange flow in the bay becomes stronger as a result of a stronger baroclinic pressure gradient.

Also, note that this density gradient between the pass and bay overcame gradients created by the local bathymetry of the bay. One might expect that with the bay gradually deepening from the closed end to the measurement station we might observe the type of thermal flow described by Monismith et al. [2006] associated with a sloping bottom. This scenario, however, would drive flows in the opposite direction, with flow in the lower layer toward the ocean at night. This indicates that if there is any density gradient associated with the bay's gently sloping bottom at the closed end, it is much weaker than the gradient between the bay and pass.

\subsection{Total Lagoon Heat Storage and Heat Balance}

Capturing the temperature changes at the different reef locations and the inflow (over the reef crest) and outflow (through the pass) over a canonical day allows us to calculate the heat balance for the reef-lagoon over a canonical day. Even with the strong input of cold ocean water coming in the bottom, the reef pass was a net exporter of heat from the reef-lagoon. Using the measurements described above, we estimated the change in thermal energy of the entire reef-lagoon system. To better understand variability in the total heat transport in the system, a volume-weighted average of temperature can be written as

$$
\rho c_{p} \frac{\partial}{\partial t} \iiint T d V=\rho c_{p} W_{P} \int U_{P}(z) T_{P}(z) d z+\rho c_{p} A_{R} U_{R} T_{R}+\iint H d A
$$
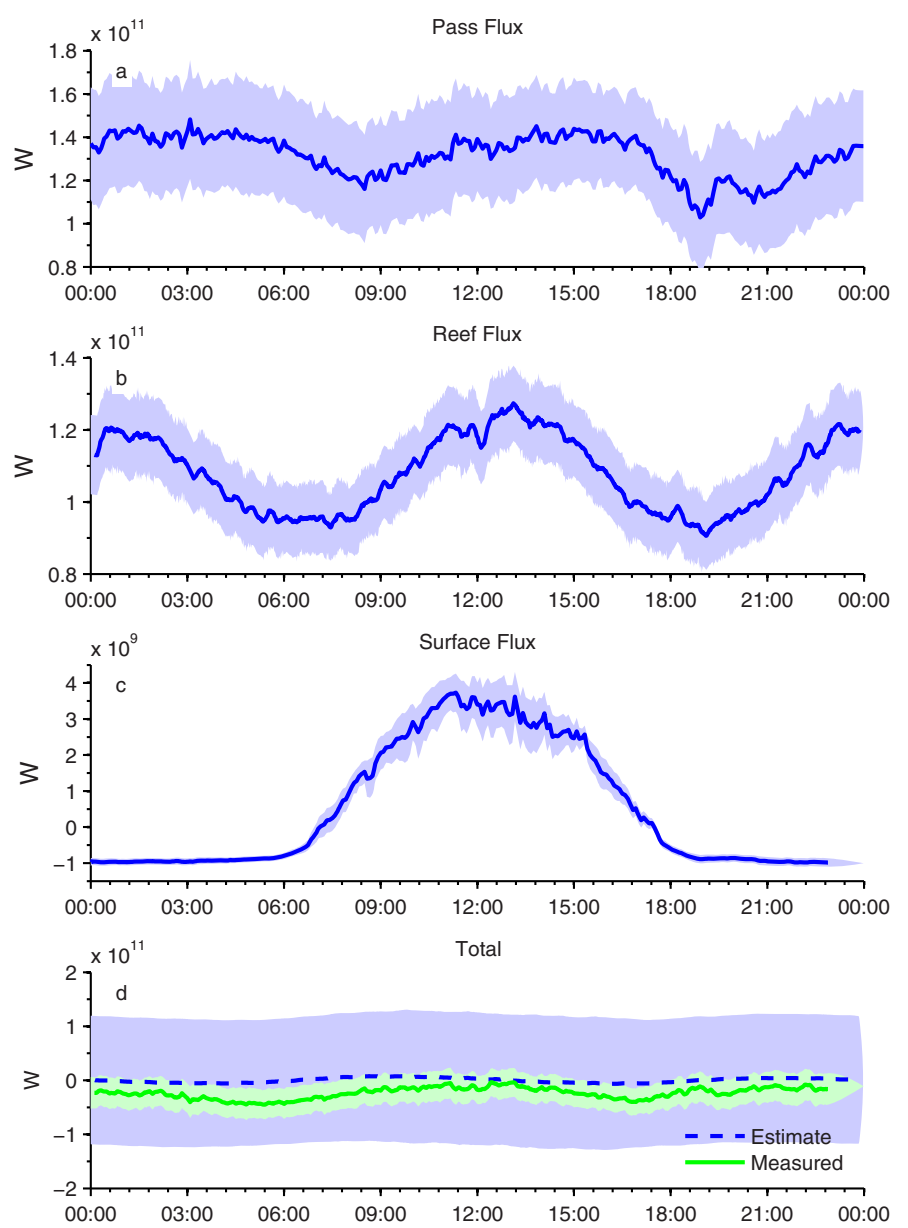

Figure 10. Thermal energy balance for entire lagoon system. (a) Heat flux out of the pass; (b) heat flux in the reef crest; (c) surface heat flux; (d) the estimate is the sum of the terms in Figures 10a, 10b, and 10c, and measured denotes a volume-weighted average of measured temperatures in the system. Shading indicates $95 \%$ confidence intervals.
In equation (11), the term on the left-hand side is the integral over the volume $(V$ ) of the system of the spatially varying temperature field $T(x, y, z)$. The first term on the right side of (11) is the flux of thermal energy out of the system through the reef pass, where $U_{P}$ and $T_{P}$ are the depthvarying velocity and temperature in the pass, respectively, and $W_{P}$ is the pass width. The second term is the flux over the reef crest where $U_{R}$ and $T_{R}$ are the velocity and temperature at $\mathrm{R} 1$ and $A_{R}$ is the area of the plane forming the influx surface, defined as the product of the water depth and length of the reef at the reef crest. The third term represents the integral over the area of the surface fluxes $(H)$. The reef pass flux was computed using phase-averaged velocity and temperature profiles from Station $P$ and assumed a pass width of $200 \mathrm{~m}$. The flux into the system used the depth and phase-averaged velocity and temperature measured just behind the reef crest (Station R1). The surface heat flux term was estimated from the surface fluxes over Stations B and R1-R3 


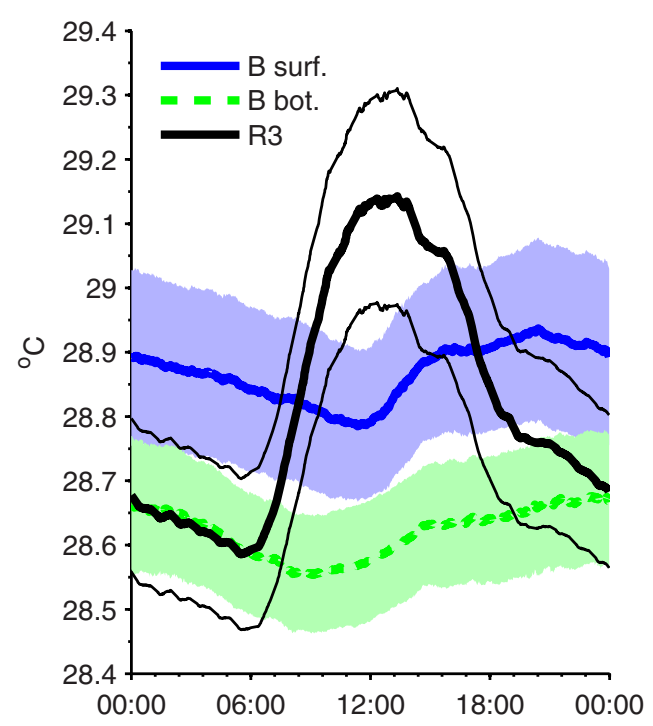

Figure 11. Diurnal temperature variability in back reef (Station R3) and bay (Station B) at surface ( $5 \mathrm{~m}$ ) and bottom (30 m). Shading and thinner lines of same color indicate $95 \%$ confidence intervals.

(Figures 5 and 8). The entire reef area contributing flow to the reef pass (East and West Back reef) was estimated to be about $3.2 \mathrm{~km}^{2}$ and the area of the bay about $2.3 \mathrm{~km}^{2}$.

The first two right-hand side terms of equation (11) (Figures 10a and 10b) show that the reef and pass terms both had semidiurnal oscillations that are not in phase with one another. The surface heat flux (Figure 10c) was an order of magnitude smaller than the advective heat fluxes. Integrating over the course of a day, the surface heat flux provided a total of 37 TJ of energy for heating. Summing up the difference in the flux terms indicated that the reef exported 37 TJ more energy than was brought in by the reef crest. Although the temperature changes in different parts of the reef are not in phase, the circulation pattern we observed creates no net change in thermal energy during the canonical day, indicating the reef system is near equilibrium in terms of temperature.

The phase difference between influx and out flux of heat indicates storage of heat in the system. Given the high rate of advection in the rest of the system, the most likely locale for heat storage is in the bay. Allowing water to enter the bay from the back reef, instead of exit directly via the pass would create the extra transit time required to explain the observed phasing differences in heat flux in and out of the system. A comparison of temperature signals from different locations supports this explanation of the circulation (Figure 11). In the early morning, the bay bottom temperature matched the temperature of the back reef, indicating the bay was being replenished at the bottom with water from the back reef. Reef and bay temperatures began to diverge around 07:00 as the back reef water started to rapidly warm, but they matched again near midnight. When the back reef water was warmer than the water at the bay surface, the flow out of the bay shut down (Figure 4). There is, of course, a lag in the temperature and velocity signals of the back reef relative to those measured in the bay due to the finite velocity and distance between stations ( $1.5 \mathrm{~km})$.

The observational data and analyses support the conclusion that there are different circulation patterns during different phases of the "canonical" day (Figure 12). An important parameter for switching between the different circulation patterns is the relative temperature between the back reef and the bay. Warm water flowing from the reef to the channel junction where the bay connects to the pass lessens and occasionally reverses the density gradient from the bay to the pass, and warm reef water flows directly out of the pass. When the reef water is colder and denser than the bay water, the density gradient between pass and bay is

NIGHT

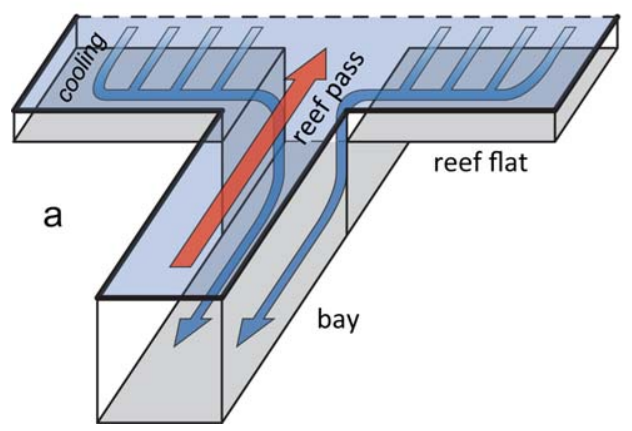

DAY

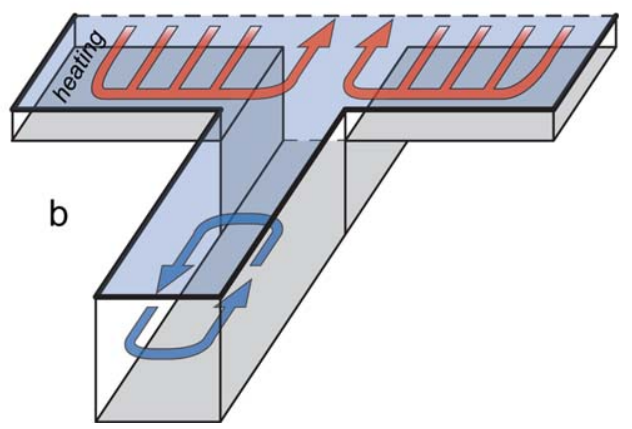

Figure 12. Schematic diagram of circulation in reef-channel-bay-pass system during (a) night and (b) day. Night is defined as the period when reef water is cooler than surface water in the bay; day has the opposite condition. 


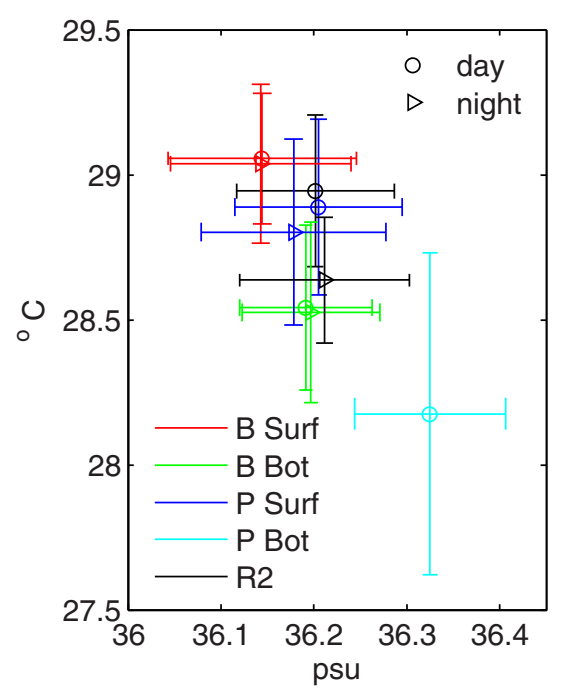

Figure 13. Average temperature and salinity at bay (B), pass (P), and reef (R2) stations. Circle markers indicate daytime average conditions; triangles are nighttime conditions. The pass bottom has only one point as there is no pattern to nighttime and daytime water properties. Error bars indicate the standard deviation around the mean. enhanced and intensifies bottom velocities into the bay (Figure 4). This is related to the momentum balance shown in Figure 6. Under these conditions, the flow of bottom water into the bay is enhanced because the baroclinic pressure gradient strengthens with depth. The free-surface gradient responds to this baroclinic forcing and forces water out at the surface. When the baroclinic and barotropic forcing are minimized, the reef water directly exits through the pass, as it is primarily subjected to the wave-driven surface gradients as described in Hench et al. [2008]. One way to confirm this flow pattern is by examining the typical water properties present (Figure 13) during the different circulation patterns at the different stations. Based on the canonical averages in the bay and pass, it appears "night" circulation occurs consistently between 0:00 and 06:00 and "day" circulation exists for a shorter duration between 12:00 and 15:00. The water properties in the bay do not change significantly during this time (Figure 13), indicating that there is no change in source for the bay water. However, there are significant differences between the water at the surface of the pass and at Station R2 when averaged over these different time periods. The pass water is very similar to the reef water during the daytime, and freshens during nighttime, which is indicative of more source water coming from the surface of the bay. The reef water is cooler at night and much closer in temperature and salinity to the water entering the bottom of the bay, and is significantly different from the water entering the surface of the pass. This change in water properties supports the circulation pattern in Figure 12, because if reef water were generally bypassing the bay to exit directly out the pass, one would expect the water properties of the pass to mimic those of the reef. The velocity profiles measured at Station $\mathrm{C}$ (not shown) are also consistent with this circulation, showing enhanced bottom velocities at the same time water is entering the bay bottom, and enhanced surface velocities when water exits directly through the pass surface.

An alternative hypothesis for the bay exchange flow is that colder ocean water enters the bay via the bottom of the pass. This appears to be unlikely though as the temperature and salinity at $20 \mathrm{~m}$ depth in the pass was significantly different from that observed in the bay (Figure 13). Also, shipboard CTD transects (not shown) did not indicate ocean water ever intruded past the side channels draining the reef. The only instance of flow from the bottom of the reef pass penetrating to the bay was on 19 January 2007 just after the end of the large rainfall event on the island. Examination of the records for times when both the pass mooring had an inward velocity at the bottom and the temperatures at the bottom of the pass and bay stations matched found only one instance of these coincident conditions, directly after the large rainfall event, which was also the longest duration of bottom inflow (1.9 days) at Avaroa Pass. The large rainfall event enhanced the exchange flow the pass by creating very strong density gradients; with more typical, temperature-driven density gradients, bottom water intrusions from the pass did not occur. It is possible that in other seasons and/or with different conditions this exchange flow in the pass extends farther in to the system and becomes important to the flushing of the bay. However, inflow from the ocean through the depth of the pass does not appear to regularly occur during the austral summer.

\section{Residence Time}

Water in the bay is regularly refreshed despite the local weakness of other common forcing mechanisms like wind, waves, and tides. Wind and waves are present in the system, but contribute only indirectly to the bay circulation through their effect on the baroclinic pressure gradient. During the observed austral summer conditions, on average, $30 \%$ of the lagoon volume was flushed in the canonical day. This flushing estimate 
assumes that the flux of water observed entering at our bay station enters across the entire bay ( $1 \mathrm{~km}$ wide) so, when integrated in time, the velocity and flux area can be converted to a volume of water entering the bay. The total volume to enter over the course of a canonical day is normalized by the total volume of water south of the bay station $\left(6 \times 10^{7} \mathrm{~m}^{3}\right)$ to calculate a percentage of new water volume. Using the same idea to estimate the new water input associated with a barotropic flow of $1 \mathrm{~mm} / \mathrm{s}$ for $12 \mathrm{~h}$ a day (an estimate of tidal flow) leads to an estimate of only $2 \%$ water volume change over the course of a day. In the Appendix $A$, there are data from the large flood event in the first summer of record. This was an extreme event, with a likely long return period, and we estimated the bay was only flushed twice in 1 day. Diurnal flushing of the bay by buoyancy-driven flows is extremely important in understanding the residence time of the system and it is comparable to the episodic flushing produced by an extreme forcing event. In previous work, it was estimated that the time between water passing over the reef crest and exiting through the pass was on the order of $3 \mathrm{~h}$ [Hench et al., 2008]. The present study shows that some of the back reef water follows an alternate path through the system. When water does not exit the pass directly, but instead flows into the bay and is stored there, the average age of a water parcel exiting the pass increases substantially. Using the simplest method of estimating residence time (volume divided by flow rate) we can estimate the increase in residence time associated with this extra storage by simply increasing the volume of the system. Because the bay is so much larger in volume than the reef, the same flow rate that translates to a $3 \mathrm{~h}$ residence time for flow through the reef and pass, results in a $30 \mathrm{~h}$ residence time if the bay is included in the volume of the system. However, this does not account for the periodic nature of the circulation. If each circulation pattern is present half the time, then sometimes water is exiting the pass $3 \mathrm{~h}$ after entering the reef crest, while at other times water exiting the pass will have spent an average of 2 days in the system. These differences in residence time may play an important role in many biogeochemical, biological, and ecological processes in reef lagoons with similarly variable bathymetry.

\section{Conclusions}

We studied Paopao Bay, which has a shallow back reef with a deep bay behind it, a common geometry in many island reef systems. The temperature difference between the bay and shallow reef areas played an important role in determining the exchange dynamics, creating distinct circulation patterns during the day and night. Although the baroclinic exchange flow in the bay was slow and relatively weak compared to the wave-driven flow occurring in other parts of the reef-lagoon-pass system, this thermally driven flow appears to be the primary mechanism of exchange between the bay and the ocean. This circulation also shows that all of the ocean water entering the bay passed through the shallow reef area first. Around the island of Moorea alone, there are eight such bays (Figure 1a) that may function similarly to that observed in Paopao Bay. Any pass exchange dynamics at each of these locations will depend on the relative depths in the back reef, lagoon, and pass systems. Although, wave-driven flow dynamics dominated the shallow back reef, the heating that occurred there had a significant effect on other parts of the system by inducing buoyancy-driven flows. We observed active circulation from horizontal temperature gradients related to the steep topography commonly found in many coral reef lagoon systems, in a variation on the "thermal siphon" circulation observed in other coastal environments.

\section{Appendix A : Freshwater Budget}

Consistent with previous work at this site [Hench et al., 2008; Monismith et al., 2013], the depthaveraged flow in the reef pass was always seaward, out of the reef and bay. The velocity in the pass was often strongly sheared, with an inflow of colder, slightly saltier water on the bottom, and an outflow of warm lagoon water at the surface (Figure 9). Because Avaroa Pass is the sole exit of the system, we can use concurrent temperature and salinity measurements made there to estimate the freshwater input to the system.

Using conservation of volume and salt, we can estimate the amount of freshwater entering the system and thus the relative importance of temperature and salinity in producing vertical stratification and horizontal density gradients. The water exiting through the pass $\left(Q_{\text {pass }}\right)$ is a combination of the water at ocean salinity 
from wave-driven flow over the reef crest $\left(Q_{\text {reef }}\right)$ and freshwater inputs to the system $\left(Q_{f w}\right)$. Ignoring evaporation, continuity implies that

$$
Q_{\text {pass }}=Q_{\text {reef }}+Q_{f w}
$$

where $Q$ is volumetric flux and subscripts indicate the source of the water. Conservation of salt $(S)$ implies that the depth integrated salinity flux out the pass is equal to the salinity coming into the pass from the reef plus that of the freshwater

$$
W_{\text {pass }} \int_{-d}^{0} U_{\text {pass }}(z) S_{\text {pass }}(z) d z=Q_{\text {reef }} S_{\text {reef }}+Q_{f w}+S_{f w}
$$

where $W$ is the reef pass width, estimated as $200 \mathrm{~m}$ to account for slower flow near the edges and assumed uniform with depth, and $U$ is the along-channel velocity in the reef pass. Equations (1) and (2) can be combined to find that

$$
Q_{\text {pass }}-\frac{W_{\text {pass }}}{S_{\text {reef }}} \int_{-d}^{0} U_{\text {pass }}(z) S_{\text {pass }}(z) d z=Q_{f w}
$$

Given that $S_{f w}=0$, we can use the salinity and velocities measured in the pass and the salinity measured at R2 as $S_{\text {reef }}$ to estimate the flow of freshwater $\left(Q_{f w}\right) . Q_{f w}$ for the two different summers is shown in Figures $A 1$ and A2. The peak of freshwater inflow was during a large storm that flooded the Paopao Valley between 14 January 2007 and 28 January 2007. Even then $Q_{f w} / Q_{\text {reef }}$ only reached 0.025 . This is due to the fact that the wavedriven flux was also high at this time. Two summers later, between 14 December 2008 and 8 February 2009, the maximum percentage of freshwater relative to the total flux determined this way was $0.7 \%$. Thus, with the exception of an exceptional flood event, freshwater inputs are generally not directly important to the volumetric fluxes through the system. Given the small size of the stream, the small volume of freshwater was expected.

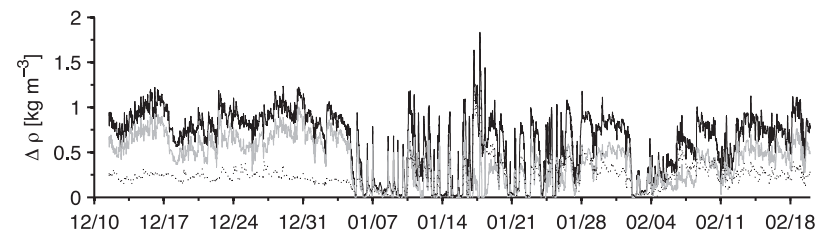

We can also estimate the contributions of temperature and salinity to both the vertical density difference $(\Delta \rho)$, defined as the bottom CTD density measurement minus the one

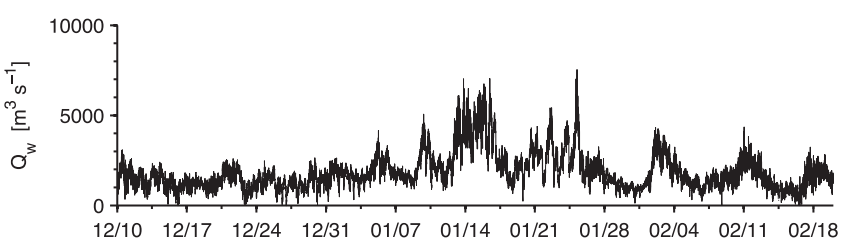
at the surface, and the buoyancy flux through the pass. The buoyancy flux per unit width of the pass is estimated by

$$
J / W=\frac{g}{\rho_{o}} \int_{-d}^{0} U(z)\left[\rho(z)-\rho_{o}\right] d z
$$

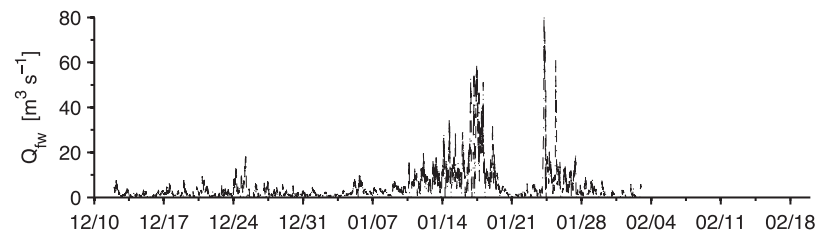

where the density at each depth is a function of both salinity and temperature. To first order, the relative contributions to buoyancy flux and stratification can be assessed by

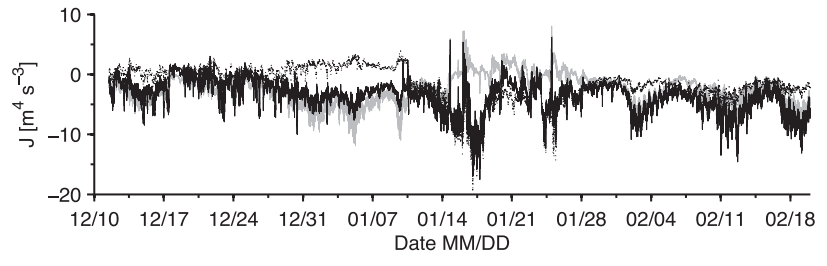
assuming that either temperature or salinity is constant and using the measured salinity and temperature to compute density variations. Even though $Q_{f w}$ was small compared to $Q_{\text {pass }}$ during the large flood event, freshwater was important to buoyancy flux and vertical stratification

Figure A1. Estimate of freshwater input and its effect for December 2006 to February 2007 measurements. (a) Density difference; (b) wave-driven flux; (c) freshwater flux; and (d) buoyancy flux. Equations (A3) and (A4) used for Figures A1c and A1d. 

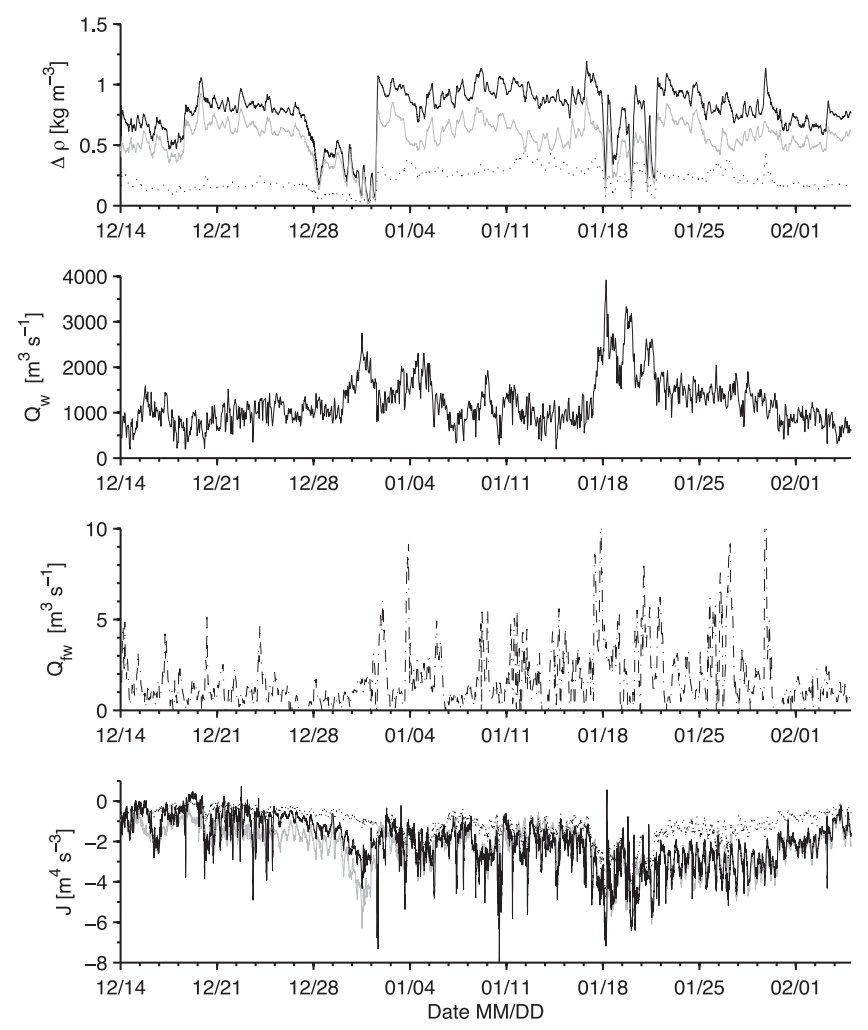

Figure A2. Same as Figure A1 for December 2008 to February 2009. density stratification in the pass is primarily associated with temperature variability.

During the second experiment (Figure A2), temperature was the primary determinant of stratification and buoyancy flux, although during some strong wave-driven flow events near 1 January 2009 and in the week of 18 January 2009 vertical stratification in the pass was almost completely eliminated. Even in the large storm event, the week of 14 January 2007, vertical stratification frequently disappeared due to the coincident strong wave-driven flows. Thus, the large freshwater contribution to buoyancy did not change the stratification as much because the barotropic wave forcing overwhelmed the exchange flow inside the pass [cf. Hench et al., 2008]. Given that the cooccurrence during local storms of high rainfall and big waves is common, we conclude that in general freshwater flows have little effect on the flows through the pass in this system.

\section{Acknowledgments}

We thank K. Davis, J. Dunckley, S. Giddings, M. Murray, N. Nidzieko, J. Rosman, A. Santoro, K. Seydel, M. Squibb, and $\mathrm{H}$. Stewart for help with the field measurements. We thank three anonymous reviewers for thoughtful comments that improved the manuscript. Support for this work came from the National Science Foundation through the Moorea Coral Reef LTER (OCE-1026851) and Physical Oceanography (OCE-0622967, OCE1061108, and OCE-1435133) programs and from the Singapore-Stanford program. The data used in this publication are available by contacting Liv Herdman (livmw@stanford.edu) or Jim Hench (jim.hench@duke.edu).

\section{References}

Arita, M., and G. H. Jirka (1987), Two-layer model of saline wedge I: Entrainment and interfacial friction, J. Hydraul. Eng., 113, 1229-1248, doi:10.1061/(ASCE)0733-9429(1987)113:10(1229).

Callaghan, D. P., P. Nielsen, N. Cartwright, M. R. Gourlay, and T. E. Baldock (2006), Atoll lagoon flushing forces by waves, Coral Reefs, 16, 269-272, doi:10.1016/j.coastaleng.2006.02.006.

Coles, S. L. (1997), Reef corals occurring in a highly fluctuating temperature environment at Fahal Island, Gulf of Oman (Indian Ocean), Coastal Eng., 53, 691-704, doi:10.1007/s003380050084.

Davies, J. M., R. P. Dunne, and B. E. Brown (1997), Coral bleaching and elevated sea-water temperature in Milne Bay Province Papua New Guinea 1996, Mar. Freshwater Res., 48, 513-518, doi:10.1071/MF96128.

Davis, K. A., J. J. Leichter, J. L. Hench, and S. G. Monismith (2008), Effects of western boundary current dynamics on the internal wave field of the southeast Florida shelf, J. Geophys. Res., 113, C09010, doi:10.1029/2007JC004699.

Davis, K. A., S. J. Lentz, J. Pineda, J. T. Farrar, V. R. Starczak, and J. H. Churchill (2011), Observations of the thermal environment on Red Sea platform reefs: A heat budget analysis, Coral Reefs, 30, 25-36, doi:10.1007/s00338-011-0740-8.

Dittko, K. A., M. P. Kirkpatrick, and S. W. Armfield (2013), Three-dimensional simulation of natural convection in a reservoir sidearm, Phys. Fluids, 25, 025105, doi:10.1063/1.4792709.

Galzin, R., and J. P. Pointier (1985), Moorea Island, Society Archipelago, in Proceedings of 5th International Coral Reef Congress, International Coral Reef Congress, Tahiti, 1, 73-102.

Glynn, P. W. (1996), Coral reef bleaching: Facts, hypotheses and implications, Global Change Biol., 2(6), 495-509, doi:10.1111/j.13652486.1996.tb00063.x.

Gramer, L. J., A. J. Mariano, and J. C. Hendee (2012), Heat budget for Florida reefs: Reef-scale thermal stress via satellite, in Proceedings of 12th International Coral Reef Symposium at the Internationa Coral Reef Symposium, Cairns, Queensland, Australia, 9-13 July.

Hearn, C. J. (1999), Wave-breaking hydrodynamics within coral reef systems and the effect of changing relative sea level, J. Geophys. Res., 104, 30,007-30,019, doi:10.1029/1999JC900262.

Hench, J. L., and J. H. Rosman (2013), Observations of spatial flow patterns at the coral colony scale on a shallow reef flat, J. Geophys. Res. Oceans, 118, 1142-1156, doi:10.1002/jgrc.20105.

Hench, J. L., J. J. Leichter, and S. G. Monismith (2008), Episodic circulation and exchange in a wave-driven coral reef and lagoon system, Limnol. Oceanogr., 53, 2681-2694, doi:10.4319/lo.2008.53.6.2681.

Herdman, L. M. M. (2012), Circulation, residence time, and retention in a tropical coral reef, PhD dissertation, 308 pp., Stanford Univ., Stanford, Calif.

Hoegh-Guldberg, O. (1999), Climate change, coral bleaching and the future of the world's coral reefs, Mar. Freshwater Res., 50, 839-866, doi:10.1071/MF99078.

Kanji, G. K. (2006), 100 Statistical Tests, SAGE, London, U. K.

Leichter, J. J., G. B. Deane, and M. D. Stokes (2005), Spatial and temporal variability of internal wave forcing on a coral reef, J. Phys. Oceanogr., 35, 1945-1962, doi:10.1175/JPO2808.1. 
Leichter, J. J., B. Helmuth, and A. M. Fischer (2006), Variation beneath the surface: Quantifying complex thermal environments on coral reefs in the Caribbean, Bahamas and Florida, J. Mar. Res., 64, 563-588, doi:10.1357/002224006778715711.

Manzello, D. P., R. Berkelmans, and J. C. Hendee (2007), Coral bleaching indices and thresholds for the Florida Reef Tract, Bahamas, and St. Croix, US Virgin Islands, Mar. Pollut. Bull., 54, 1923-1931, doi:10.1016/j.marpolbul.2007.08.009.

Mao, Y., C. Lei, and J. C. Patterson (2009), Unsteady near-shore natural convection induced by surface cooling, J. Fluid Mech., 642, 213-233, doi:10.1017/S0022112009991765.

Maritorena, S., A. Morel, and B. Gentili (1994), Diffuse reflectance of oceanic shallow waters: Influence of water depth and bottom albedo, Limnol. Oceanogr., 39, 1689-1703.

McCabe, R. M., P. Estrade, J. H. Middleton, W. K. Melville, M. Roughan, and L. Lenain (2010), Temperature variability in a shallow, tidally isolated coral reef lagoon, J. Geophys. Res., 115, C12011, doi:10.1029/2009JC006023.

McClanahan, T. R. (2002), The near future of coral reefs, Environ. Conserv., 29, 460-483, doi:10.1017/S0376892902000334.

McCook, L. J. (1999), Macroalgae, nutrients and phase shifts on coral reefs: Scientific issues and management consequences for the Great Barrier Reef, Coral Reefs, 18(4), 357-367, doi:10.1007/s003380050213.

Molina, L., G. Pawlak, J. R. Wells, S. G. Monismith, and M. A. Merrifield (2014), Diurnal cross-shore thermal exchange on a tropical forereef, J. Geophys. Res. Oceans, 119, 6101-6120, doi:10.1002/2013JC009621.

Monismith, S. G. (2014), Flow through a rough, shallow reef, Coral Reefs, 33(1), 99-104, doi:10.1007/s00338-013-1107-0.

Monismith, S. G., J. Imberger, and M. L. Morison (1990), Convective motions in the sidearm of a small reservoir, Limnol. Oceanogr., 35, 1676-1702, doi:10.4319/lo.1990.35.8.1676.

Monismith, S. G., A. Genin, M. A. Reidenbach, G. Yahel, and J. R. Koseff (2006), Thermally driven exchanges between a coral reef and the adjoining ocean, J. Phys. Oceanogr., 36, 1332-1347, doi:10.1175/JPO2916.1.

Monismith, S. G., L. M. M. Herdman, S. H. Ahmerkamp, and J. L. Hench (2013), Wave transformation and wave-driven flow across a steep coral reef, J. Phys. Oceanogr., 43, 1356-1379, doi:10.1175/JPO-D-12-0164.1.

Nadaoka, K., Y. Nihei, R. Kumano, T. Yokobori, T. Omija, and K. Wakaki (2001), A field observation on hydrodynamic and thermal environments of a fringing reef at Ishigaki Island under typhoon and normal atmospheric conditions, Coral Reefs, 20, 387-398, doi:10.1007/ s00338-001-0188-3.

Niemann, H., C. Richter, H. M. Jonkers, and M. I. Badran (2004), Red Sea gravity currents cascade near-reef phytoplankton to the twilight zone, Mar. Ecol. Prog. Ser., 269, 91-99, doi:10.3354/meps26909.

Ong, R. H., A. J. C. King, B. J. Mullins, T. F. Cooper, and M. J. Caley (2012), Development and validation of computational fluid dynamics models for prediction of heat transfer and thermal microenvironments of corals, PLOS ONE, 7, e37842, doi:10.1371/journal.pone.0037842.

Pawlowicz, R., B. Beardlsey, S. Lentz, E. Dever, and A. Anis (2001), Software simplifies air-sea data estimates, Eos Trans. AGU, 82, 2, doi: 10.1029/01EO00004.

Payne, R. E. (1972), Albedo of the sea surface, J. Atmos. Sci., 29, 959-970, doi:10.1175/1520-0469(1972)029<0959:AOTSS>2.0.CO;2.

Physick, W. (1976), A numerical model of the sea-breeze phenomenon over a lake or gulf, J. Atmos. Sci., 33, 2107-2135, doi:10.1175/15200469(1976)033<2107:ANMOTS > 2.0.CO;2.

Rosman, J. H., and J. L. Hench (2011), A framework for understanding drag parameterizations for coral reefs, J. Geophys. Res., 116, C09010, doi:10.1029/2010JC006892.

Sammarco, P. W., A. Winter, and J. C. Stewart (2006), Coefficient of variation of sea surface temperature (SST) as an indicator of coral bleaching, Mar. Biol., 149, 1337-1344, doi:10.1007/s00227-006-0318-0.

Smith, N. (2001), Weather and hydrographic conditions associated with coral bleaching: Lee Stocking Island, Bahamas, Coral Reefs, 20, $415-$ 422, doi:10.1007/s00338-001-0189-2.

Sternberg, R. W. (1968), Friction factors in tidal channels with differing bed roughness, Mar. Geol., 6, 243-360, doi:10.1016/00253227(68)90033-9.

Wells, J. R., J. P. Fram, and G. Pawlak (2012), Solar warming of near-bottom water over a fringing reef, J. Mar. Res., 70, 641-660, doi:10.1357/ 002224012805262734.

Yelland, M., and P. Taylor (1996), Wind stress measurements from the open ocean, J. Phys. Oceanogr., 26, 541-558, doi:10.1175/15200485(1996)026<0541:WSMFTO > 2.0.CO;2.

Zhang, Z., J. Falter, R. Lowe, G. Ivey, and M. McCulloch (2013), Atmospheric forcing intensifies the effects of regional ocean warming on reef-scale temperature anomalies during a coral bleaching event, J. Geophys. Res. Oceans, 118, 4600-4616, doi:10.1002/jgrc.20338. 